\title{
Past and recent trends in the western Black Sea storminess
}

\author{
N. N. Valchev, E. V. Trifonova, and N. K. Andreeva \\ Institute of Oceanology - Bulgarian Academy of Sciences, Varna, Bulgaria \\ Correspondence to: N. N. Valchev (valchev@io-bas.bg)
}

Received: 20 September 2011 - Revised: 2 February 2012 - Accepted: 20 February 2012 - Published: 13 April 2012

\begin{abstract}
Storms are one of the most important phenomena producing coastal hazards and endangering human life and activities. In recent decades storm climate has become a subject of increased public awareness and knowledge of this issue can help the society to meet future challenges related to extreme storm manifestation. Therefore, the goal of this study is to assess trends in past and recent storminess in the western Black Sea. The analysis of storm climate is based on a continuous hindcast dataset covering a substantial historical time-span of $63 \mathrm{yr}$ (1948-2010). It was used to create a storm population and to estimate properties describing storminess (proxies). This was done by introduction of criteria allowing separation of events with low probability of occurrence and at the same time keeping the information on their pattern, i.e. properties of storm phases. Eleven storminess proxies were analysed and the most indicative appeared to be storm duration; integral, mean and specific storm wave energy; and wind velocity and direction, which were obtained for each storm season.

While experiencing significant variability on a quasidecadal scale, no significant upward or downward trends in storminess were detected. For almost all proxies, an increasing trend until the 1980s or the 1990s and a return to average or even calm conditions in the late 2000s are traceable. On this background, a steady although not significant increase of wind velocity was detected. Results also indicate an alteration of storm pattern, manifested as shortening of storm duration due to a shift of the prevailing direction of storm forcing winds to the north. Nevertheless, incident wave energy in the storms' most intense phase remains significant. The obtained results are discussed with regard to the influence of the North Atlantic Oscillation on the hydrometeorological pattern of the Black Sea region as a part of the EuropeanAtlantic area, in particular with respect to the cyclonic activity.
\end{abstract}

\section{Introduction}

Severe storms and heavy seas represent major hazards for navigation and offshore activities. Equally, coasts have always been vulnerable to storms that can affect adversely the population and shore based industries, destroy coastal defense, inland property and infrastructure, and most importantly can damage the coastal environment.

In the last decades, coastal regions have undergone dynamic environmental and socio-economical changes. It has been estimated that $23 \%$ of the world's population lives both within $100 \mathrm{~km}$ distance of the coast and less than $100 \mathrm{~m}$ above the sea level, and population density in the coastal regions are about three times higher than the global average (Nicholls et al., 2007). As for the Bulgarian coast, $9 \%$ of population inhabits coastal areas (Balev, 2002). Moreover, according to the latest census in Bulgaria the population in the largest coastal cities Varna and Burgas had increased for the past $10 \mathrm{yr}$ with $7 \%$ and $4.1 \%$, respectively; although the total population growth of the nation is negative $-6.8 \%$ (NSI, 2011).

Due to storm impact on the coastal environment in general and on socio-economics in particular, storm climate has become a subject of increased public interest. The knowledge of trends in storminess is supposed to increase the preparedness of population and authorities to meet the impact of possible extreme events in the future by improving adaptation and mitigation strategies. This motivation led us to study the changes in occurrence and magnitude of marine storms in the western Black Sea during the last $60 \mathrm{yr}$.

Starting from worldwide perspective, lots of efforts were dedicated to study long-term climatic trends of various meteorological and oceanic parameters in the past $20 \mathrm{yr}$. Some positive trends in wind wave height in various seas have been attributed to variability of the wind regime (e.g. Dolan et al., 1989). Most of the studies refer to the northeast Atlantic and northeast Pacific Oceans. Some earlier investigations 
were based on either instrumental measurements (Carter and Draper, 1988; Bacon and Carter, 1991) or wave hindcast over periods of various rather short-term spans - from single storms (e.g. Cardone et al., 1996) to a couple of decades (Kushnir et al., 1997; Sterl et al., 1998). Other studies consider longer records of homogeneous variables such as sea level pressure (Schmith, 1995). They revealed a longterm stationarity in storm statistics during the last $100 \mathrm{yr}$, which, however, exhibit a significant decadal variability; as a minor worsening in storm climate is evident only during the last four decades of the 20th century.

Storms are usually associated with an approaching or developing cyclone. Examining the distinctive circulation patterns of storminess on the Atlantic margin of Europe, Lozano et al. (2004) used coastal meteorological data series from Ireland to Spain, covering time-span of about $60 \mathrm{yr}$. They studied climatology of the extratropical cyclones, in particular linking the cyclone history for the North Atlantic with storm frequency, intensity and tracking. Results indicate a seasonal shift in the wind climate, with regionally more severe winters and calmer summers established.

Assessment of historical wind and wave conditions covering a considerable time-span were published as long as the results of global atmospheric reanalysis projects became available in the second half of the 1990s. For instance, the European project WASA (Waves and Storms in the North Atlantic) was launched to explore assumption of a worsening storm and wave climate in the northeast Atlantic and its adjacent seas in the last century (WASA Group, 1998). Its main conclusion is that storm and wave climate has undergone significant variations on time scales of decades, roughening in recent ones, but with seemingly decreasing intensity of storms that become comparable with that in the beginning of the period under consideration. Cox and Swail (2001) presented the first 40-yr global wave simulations derived from the National Centers for Environmental Prediction/National Center for Atmospheric Research (NCEP/NCAR) reanalysis of surface wind fields. Their analysis showed well-defined areas of statistically significant increasing trend in the northeast Atlantic, and decreasing trend in the central North Atlantic for wind and waves. Later on, a global wave hindcast was produced within the ERA-40 reanalysis project as well (Sterl and Caires, 2005).

Similar is the conclusion of a study on European storminess from late nineteenth century to the present (Matulla et al., 2008), stating that although significant alteration on a quasi-decadal timescale was present in Europe's storm climate, most recent years are characterized by a return to average or even calm conditions. Climate estimates derived by voluntary observing ships data (e.g. Gulev et al., 2003) have added value to assessment of changing wind and wave conditions on a global scale. The overall conclusion suggests worsening of the ocean wave climate.

It is well known that dynamical modelling of the regional atmospheric and wave fields is an alternative to the use of spatially scattered and often inhomogeneous observations, and represent a step forward in understanding the coastal climate variations. An example is dynamical downscaling of the NCEP/NCAR global re-analysis to the European region performed by Feser et al. (2001), which resulted in generation of a 40-yr dataset by means of the regional atmospheric model REMO. Two studies on the North Sea storminess are based on this dataset. Weisse et al. (2005) estimated long-term changes of near-surface winds whereas Weisse and Günther (2007) focused on extreme wave conditions. Both studies concluded that related storminess proxies had increased until about 1990-1995 and decreased afterwards. It is, however, unclear whether the downward trends in wave heights and storminess in general will continue within the forthcoming years, or a reinforcement of storm activity will occur.

Wind and wave climate of the Black Sea has been investigated more actively in the past $50 \mathrm{yr}$. Results of early research were published in several handbooks, monographs and atlases (e.g. Rzheplinkskij, 1969; Sorkina, 1974; Simonov and Altman, 1991). However, presented statistical estimates were based on limited and irregular field data that resulted in a large uncertainty of obtained wind and wave regime. Later on, the international research project NATO TU-WAVE was launched with the aim to reconstruct the long-term extreme wind and wave climate of the Black Sea basin (Özhan and Abdalla, 1998). Wave hindcast simulations covering periods of various lengths (from 8 to $20 \mathrm{yr}$ ) were carried out, employing different models and eventually a wave atlas was created (Özhan et al., 2003).

There is an extensive amount of information on storms in the western Black Sea. Some fundamental aspects of statistical and spectral properties of wind waves, with examples referring to the study region, can be found in Davidan (1995). Trifonov and Trifonova (1988) made a classification of typical synoptic situations resulting in severe storms. The classification was elaborated on the basis of meteorological and synoptic data covering the period 1973-1986, which is characterized by a number of heavy storms that took place in the western Black Sea. Belberov et al. (1992) investigated extreme wave conditions with intention to create an atlas. They adopted methodology employing meteorological stations' data to create a dataset of gridded wave fields. Later on, Cherneva et al. (2008) presented results on adaptation of WAM model forced with REMO wind fields for the Black Sea, however, with no reference to the past wave climate. Application of different wind forcing and resulting wave field's quality for the western Black Sea is discussed in Davidan et al. (2006). Results on numerical predictions of extreme wave conditions with focus on storms hitting the area of interest are presented, for instance in Rusu et al. (2006). Furthermore, analysis of wave climate and assessment of wave energy potential of the western Black Sea is proposed in Rusu (2009). In order to round off the regional literary review, which does not claim to be exhaustive, 
several local publications describe imminent storms that occurred in the late 1970s and their impact on the coastal environment and defense (e.g. Vassilev, 1980; Stakev, 1980).

Storm surges and wave action may affect significantly the coastal environment, especially in terms of erosion and sediment transport patterns (Duffy and Devoy, 1999; Cooper et al., 2004). Therefore, an important aspect of changes in the storminess is the impact on the erosion and related coastal vulnerability. Extreme storms can provoke disastrous consequences such as dune destruction (Ferreira et al., 2009), sediment transport beyond the surf zone to unusual depth (Budillon et al., 2006), or burial of benthic biota (Steward et al., 2006). It is reported that changes in storm induced wave action could alter the rates of sediment dynamics and resilience of coastal systems (Regnauld et al., 1999; Sánchez-Arcilla et al., 2000; Lozano et al., 2004). However, this key issue is not in the focus of the present study. Detailed analysis of morphological impact of the storms in the western Black Sea can be found in Trifonova et al. (2012).

Another important point in the recent studies on storminess worldwide is the relationship between cyclone activity and the major modes of interannual-to-interdecadal weather and climate variability. The dominant mode affecting midlatitudes is the North Atlantic Oscillation (NAO), which has a particular influence on meteorological and hydrological characteristics of the European-Atlantic region during the cold half of the year (Hurrell and van Loon, 1997; Jeffrey, 1997; Polonsky et al., 2004; Marshall et al., 2011). According to the well-known mechanism, the NAO is responsible for intensification of zonal circulation and for the shift of the North Atlantic storm tracks. In the positive NAO phase, storm tracks shift to Northern Europe and anticyclonic activity prevails over Central and Southern Europe, and the Mediterranean, while in its negative phase the opposite situation takes place - most of the storm tracks displace to Eastern Europe and the Mediterranean and more anticyclones occur over Northern Europe. Correspondingly, higher winter temperature and wet conditions are observed in the Northern and Central Europe, while over its southern part, including the Black Sea region, weather tends to be dryer and colder during the positive NAO phase (Polonsky et al., 2007).

NAO influence on the interannual variability of cyclonic activity in the Black Sea region was also studied by Bardin et al. (2005) and Voskresenskaya and Maslova (2011). It was found that extreme hydrometeorological phenomena in the Black Sea region such as stormy winds and waves, snowstorms and heavy rains usually coincide with the peaks of the interannual-to-interdecadal signal of the coupled oceanatmosphere system; represented not only by NAO but also by AMO (Atlantic Multidecadal Oscillation), ENSO (El Niño/Southern Oscillation) and PDO (Pacific Decadal Oscillation) indices.

The present study is based on several earlier studies on wave modeling and climate (e.g. Valchev et al., 2007, 2008), but extends them in terms of both hindcast time-span and ap- proach. The goal is to assess likely trends in storminess in the western Black Sea covering a substantial historical time period. The considered agents, whose trends are examined, include near-surface winds, storm wave heights and their energy. Additionally, their seasonal variability is linked to the NAO on the basis of recently published studies referring the Black Sea region.

\section{Western Black Sea shelf: geographical setting and wind wave climate frame}

The Black Sea is an elliptical semi-closed basin with quite complex orography (Fig. 1). The area of the Black Sea shelf is about $24 \%$ of the total basin area, and its outer edge can be traced along the 100-150 $\mathrm{m}$ depth contour. The western shelf slope is relatively smooth with clearly marked shoaling (Mishev et al., 1978).

Considerable seasonal variability is the most marked feature of wind and wave climate in the western Black Sea. Synoptic processes over the seas determine wind regimes, which are classified into several types, in a manner that a particular atmospheric pressure field over Europe corresponds to each wind field type (Sorkina, 1974; Trifonov and Trifonova, 1988). Three of them are most relevant to the western Black Sea since they refer to the main directions of winds with the greatest probability of occurrence and velocity magnitude. In particular, during storm seasons, the most relevant configuration is determined by the mutual position, displacement and resulting interactions between the Mediterranean cyclones and the Eastern European (Siberian) anticyclone.

In the western Black Sea, the most intense and frequent winds directed onshore are those from NE, E and SE. Having the largest fetch, they trigger the severest storms. Winds from the NE prevail in the northern and central sections of the shelf zone, while the impact of eastern winds increases southward. Usually, southeast winds are less significant in terms of intensity but are still of importance in particular for the northern shelf portion (Valchev et al., 2008).

Following the wind pattern, waves propagate most frequently from E, NE and SE. The east waves are predominant within the entire shelf zone, ranging between $30 \%$ and $40 \%$ probability of occurrence. The fraction of northeastern waves remains nearly constant $(\sim 30 \%)$, except for the most northern portion due to sheltering effect of the cape Kaliakra. The northeastern waves affect mostly the central and southern part of the shelf. On the contrary, the importance of the southeastern waves augments northward: their probability of occurrence increases from $5 \%$ in the southern portion to more than $10 \%$ in the northern (Valchev et al., 2008).

\section{Data and methods}

Wave measurements covering large areas in extreme conditions are difficult to be performed, therefore, sufficiently 


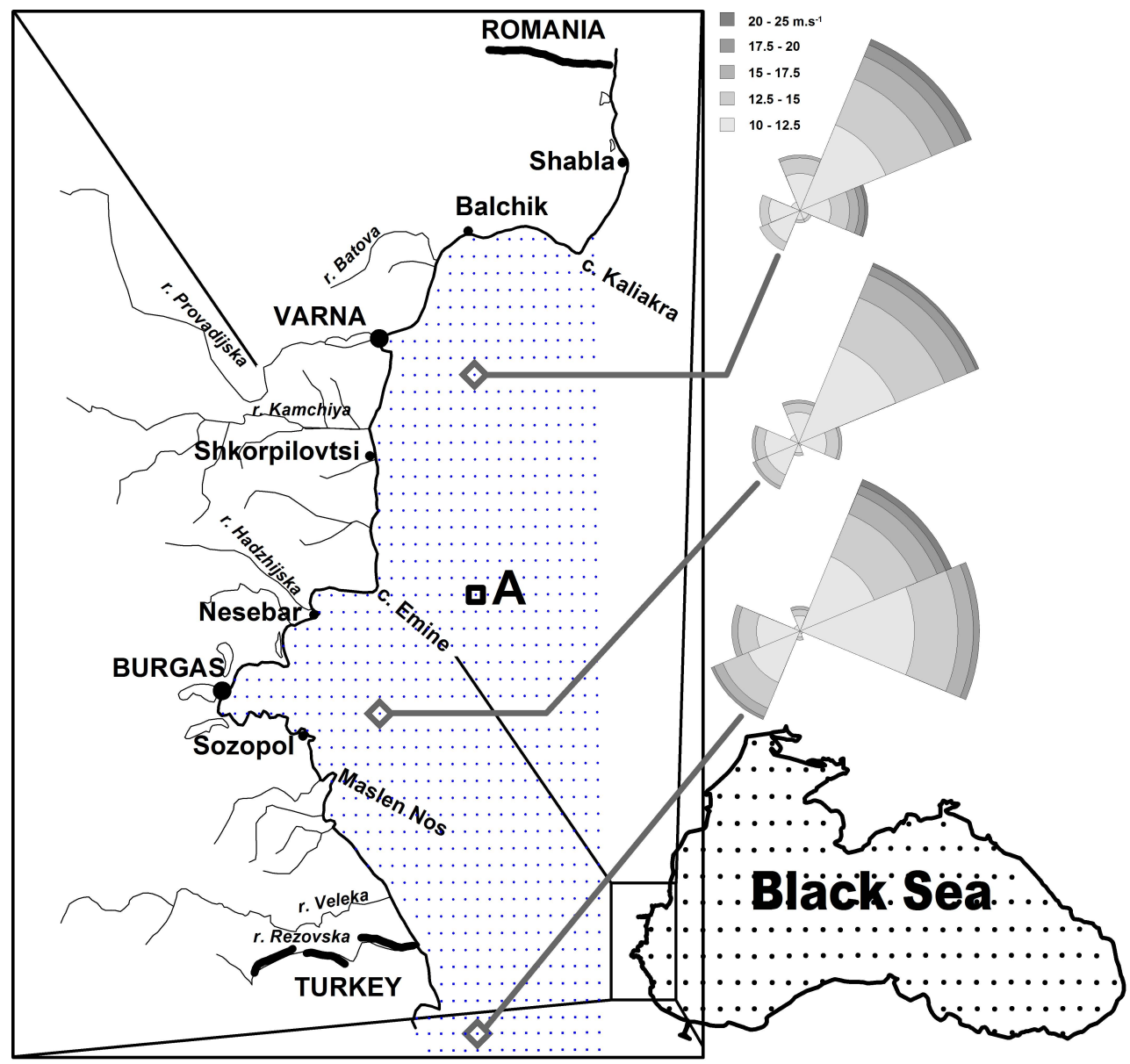

Fig. 1. Location of the study area with modelling grids for the Black Sea and its western shelf. The location of the grid point for which storm properties were estimated is denoted by letter A. Wind roses (wind velocity $>10 \mathrm{~m} \mathrm{~s}^{-1}$ ) for northern, central and southern portions of the shelf are constructed after Valchev et al. (2008).

large datasets are rare for specific basins such as Black Sea. As mentioned in the introduction, such hold-back can be overcome by numerical hindcast. This approach allows wave conditions, which occurred as far in the past as possible, to be calculated on the basis of continuous meteorological forcing. The main advantages of global reanalysis data are their physical consistency and relatively high temporal coverage. The problem of inhomogeneity is not expected; although, the use of these data for regional climate studies presents some limitations due to their coarse spatial resolution (WASA Group, 1998).

In this paper, hindcast model results were used to create a population of storms and to estimate properties describing the storminess (proxies), which were then analysed to identify likely trends. The use of model results solely allows direct analysis of storm characteristics that otherwise would only be possible after assessment of consistency of different sets of measured data or their possible combination with model data.

\subsection{Modelling approach}

Due to absence of regular long-term measurements of wind and wave conditions in the western Black Sea, the analysis of storm climate is based on continuous hindcast data series spanning $63 \mathrm{yr}$ (1948-2010). The global sea level pressure reanalysis carried out by the European Centre for Medium-range Weather Forecast (Uppala et al., 2005) and complemented by the NCEP/NCAR (Kalnay et al., 1996) was used in order to calculate the historical wind forcing for wave models. This was done by means of an atmosphericocean interaction model described in Lavrenov (1998). Since global fields have rather coarse resolution $\left(2.5^{\circ}\right.$ spatial and $6 \mathrm{~h}$ temporal), they were downscaled to the Black Sea domain. As a result, the obtained hourly gridded wind fields have $0.5^{\circ}$ resolution.

Wave conditions were modelled using a coupled system of third generation spectral wave models. The WAM model (Günther et al., 1992) was run on a regular spherical grid, covering the entire Black Sea basin at $0.5^{\circ}$ spatial 
resolution. The deep-water settings were applied with source and propagation time steps set to $10 \mathrm{~min}$ and $20 \mathrm{~min}$, respectively.

The SWAN Cycle III model, version 40.72 (SWAN Team, 2008), was set up for wave simulations in the western shelf zone. It is nested to WAM as its output provides conditions in terms of significant wave height, mean wave period, and mean direction of wave propagation on a number of points along the external boundary. SWAN is a numerical model that provides realistic estimates of wave parameters (Booij et al., 1999). The model is based on the wave action balance equation. The frequency space generated in the numerical simulations had 32 frequencies between $0.0521 \mathrm{~Hz}$ and $1 \mathrm{~Hz}$ and 36 directional bands. The model domain covers the area between $27.5^{\circ} \mathrm{E}-28.5^{\circ} \mathrm{E}$ and $41.4^{\circ} \mathrm{N}-43.4^{\circ} \mathrm{N}$ with a grid spacing of $1 / 30^{\circ}$ that results in about 1000 output sea grid points. Model grids are shown in Fig. 1. SWAN model was run in non-stationary mode in monthly packets as the warmup period was set to five days of preceding month. The output of total sea, wind sea and swell parameters were obtained hourly. Only total sea data were considered for analysis of trends.

Results of WAM validation can be found in Valchev et al. (2004) and Cherneva et al. (2008), whilst validation of SWAN is presented in Valchev et al. $(2007,2008)$. Models' validation showed good agreement between the hindcast model results and observations taken at several offshore measuring platforms.

Logically, storm conditions at the coast are much more important in determining the coastline response to likely change in forcing agents' intensity than the offshore conditions. However, in order to identify the common trend in storminess, it is preferable to choose a location where the signal is not distorted by the influence of specific local geomorphic setting. Therefore, for the purposes of the present study, a continuous hourly time series of wind (velocity and mean direction) and wave (significant height and mean direction of propagation) parameters were extracted for a location in the central part of the shelf but at the same time not too far from the coast at depth of about $70 \mathrm{~m}$ (Fig. 1). It is representative in relation to all important wind directions, for which the fetch length is more than $500 \mathrm{~km}$.

\subsection{Storm population}

Identification of a population of storm events is assumed to be the main issue. For the purpose of the study, we created a storm population out of the available data as, for example, in Berek et al. (2000). In a previous study, Valchev and Trifonova (2009), using a similar dataset, set a threshold that allows all events having morphological impact on the coast to form a population. However, if we had followed the same approach, way too many events would have been taken into consideration, which might have affected the analysis of the extreme storms' pattern. Therefore, we adopted another set

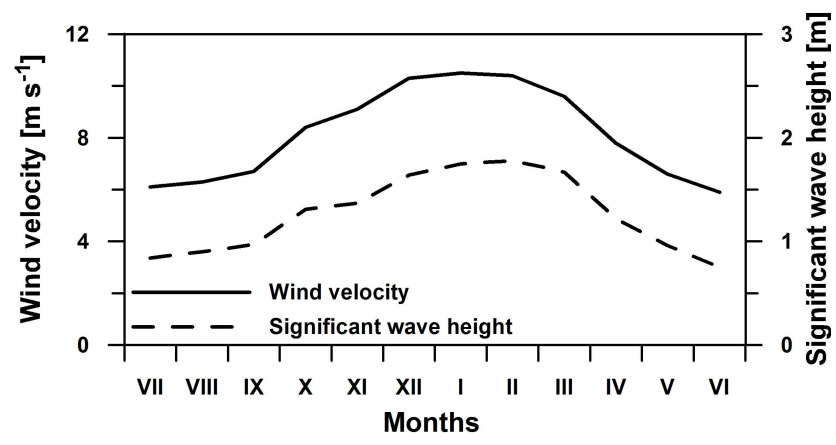

Fig. 2. Monthly $75 \%$-iles of wind velocity and significant wave height calculated for the studied dataset.

of criteria allowing separation of events with low probability of occurrence, and at the same time, keeping the information on their pattern.

Herein, the identification of storms was based primarily on wind data. Only winds within directional segment $0 \div 180^{\circ}$ were considered since they are directed shoreward, and hence, potentially result in heavy seas. Two criteria for storm identification were set up. The first one corresponds to $75 \%$-iles of wind velocity and significant wave height. Results of calculation of studied dataset's monthly $75 \%$-iles are presented in Fig. 2. Average of $75 \%$-iles of wind velocity and significant wave height for a storm season duration (roughly October - March) is about $10 \mathrm{~m} \mathrm{~s}^{-1}$ and $1.6 \mathrm{~m}$, respectively. Therefore, these values are considered as storm limiters. It should be mentioned that due to storm development and decay patterns they were not applied jointly: most often the wind limiter was applied to the development phase while the wave one - to the decay phase. Nevertheless, application of these limiters did not result in a considerable reduction of the number of storms; still quite an amount of events with widely varying duration - from tens of hours to ten days - fell within the limits. Hence, the identification of a suitable storm population implied introduction of a second threshold.

In Belberov et al. (1992) storms are considered only those events in the course of which wind velocity exceeds $15 \mathrm{~m} \mathrm{~s}^{-1}$ for at least three standard synoptic terms $(18 \mathrm{~h})$. Similar threshold was set by Lozano et al. (2004) while studying storm tracks along the Atlantic margin of Europe. We adopted that assumption by introducing a second criterion, which is that wind velocity has to exceed $15 \mathrm{~m} \mathrm{~s}^{-1}$ for a period of time $\geq 24 \mathrm{~h}$. The duration was modified with respect to Belberov et al. (1992), since according to the World Meteorological Organisation wave forecasting guide (WMO, 1998) this is the time needed for this particular wind regime to become quasi-stationary. Further, this implies that the fetch length has to be at least $500 \mathrm{~km}$ and deep-water significant wave height - of the order of $5 \mathrm{~m}$. As mentioned above the former is valid for the central part of the western shelf, while the latter is considered as "add-on" to the second 


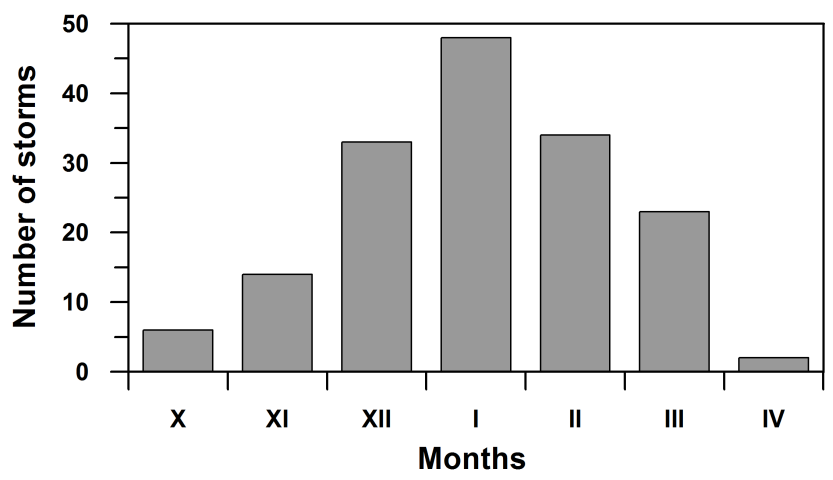

Fig. 3. Monthly distribution of the selected storms for 1948-2010.

threshold, so that: (1) if duration of an interval with wind velocity greater than $15 \mathrm{~m} \mathrm{~s}^{-1}$ was somewhat less than $24 \mathrm{~h}$ but wave height exceeded $5 \mathrm{~m}$, then the storm was included in the population; and (2) if the duration of that interval was about $24 \mathrm{~h}$ but wave height did not exceed $5 \mathrm{~m}$, then the storm was discarded. The latter case represents negligible part (about $3-4 \%$ ) of all events.

In general, the described set of criteria represents the necessary and sufficient conditions for a storm to become part of the population. In particular, the second threshold was also assumed to define the duration of the second storm phase that is the developed sea. According to data during this phase the wave growth/decay rate was observed to be less than 10$30 \mathrm{~cm}$ per hour, depending on the storm intensity. In that manner, besides the storm as a whole, the adopted methodology allowed catching variability of its phases as well, thus making it possible to trace likely changes of the storm pattern.

Accordingly, available model wind and wave data were threshold leveled to differentiate storms and their phases. Finally, 160 storms were selected from the 63-yr period, which makes less than three events per season on the average. The monthly distribution of these storms is presented in Fig. 3. The stormiest months appear to be January, February and December closely followed by March. The number of severe storms in November and October are 3 to 9 times less, respectively. Hence, a storm season is assumed to last from October to March. Therefore, in this study we consider storm seasons rather than calendar years. Thus, a misinterpretation of the overall storm season intensity is avoided. It should be mentioned that two of the selected storms occurred in April. Although, out of predefined storm season span these spring events were added to the storm population because of their particular intensity.

\subsection{Storminess proxies}

Different wind and wave characteristics are usually used to quantify storminess. In general, they refer to frequency, duration and intensity of storm properties such as wind veloc- ity, wave height and wave energy, and are called storminess proxies. In order to reveal trends in past and more recent storminess in the western Black Sea, alterations in pattern of a number of proxies during a historical period of 63 storm seasons were analysed. These are number of storms, storm duration, and integral and mean storm wave energy, which were obtained for every storm season.

By integral storm wave energy, hereafter "wave energy", we consider a result of summation of estimated deep-water wave energy hourly values over the storm duration, $E_{\Sigma}$ $\left[\mathrm{J} \mathrm{m}^{-2}\right]$, while mean wave energy is the integral energy divided by the storm duration in hours, $E_{\mathrm{m}}\left[\mathrm{J} \mathrm{m}^{-2}\right]$

$$
\begin{aligned}
& E_{\Sigma}=\sum_{i=1}^{N} \frac{1}{16} \rho g\left(H_{\mathrm{S}}\right)_{i}^{2} \\
& E_{\mathrm{m}}=\frac{1}{N} \sum_{i=1}^{N} \frac{1}{16} \rho g\left(H_{\mathrm{S}}\right)_{i}^{2}
\end{aligned}
$$

where $\rho=$ water density, $g=$ acceleration due to gravity, $H_{\mathrm{S}}=$ significant wave height, $N=$ number of stormy hours. These two properties do not represent wave energy density explicitly but have the meaning of energy indices.

Total and average of the above proxies were calculated. By total we assume the sum of mentioned proxies' values for all storms for a given season, while average is the total divided by the number of storms occurred in the same season. The average accounts for the storm pattern in particular, whereas the total - accounts for the overall storm intensity for a given season. Described calculations were done not only for storms as a whole but also for each of the three storm phases (growth, developed sea and decay).

Another proxy introduced in this study is specific storm wave energy $\left(E_{\mathrm{spf}}\right)$. It represents the ratio between the mean wave energy and the storm duration for each season. This proxy gives a notion about the rate of change of mean storm energy per unit of time in the course of the event, regardless of the actual storm duration. In addition, other proxies like maximum and mean wind velocity and significant wave height, as well as, mean wind and wave direction were studied in order to detect possible changes in the storm pattern.

In order to isolate the high-frequency signal, a low-pass filter (LPF) was applied to the proxies' seasonal time series. Linear trends with their rate of change per decade, as well as, their coefficients of determination $R^{2}$ were also calculated.

\section{Results}

In this section nine proxies' trends were examined. Overall linear trend suggests decrease in the number of storms (Fig. 4). However, a more detailed analysis reveals existence of three well marked sub-periods with somewhat uniform number of storms divided by spans of relatively 


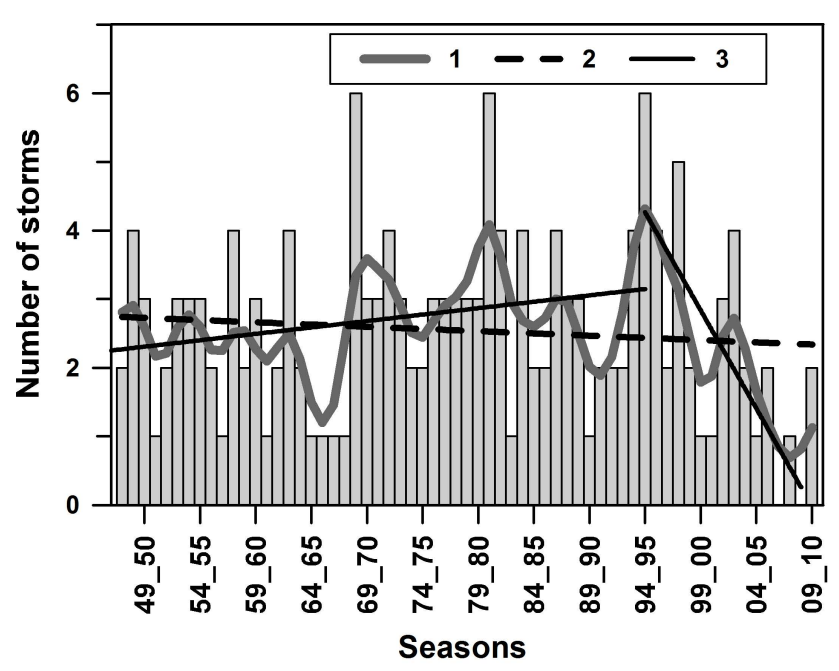

Fig. 4. Number of storms within storm seasons during 1948-2010: 1 - LPF approximation, 2 - global linear trend $\left(-0.06\right.$ storms decade $\left.{ }^{-1}, R^{2}=0.008\right), 3$ - local linear trends - upward $\left(0.19\right.$ storms decade $\left.{ }^{-1}, R^{2}=0.04\right)$, downward (2.9 storms decade $^{-1}, R^{2}=0.51$.)

calm storm conditions: until 1964, 1968-1989 and since 1993. During the first sub-period the total number of storms was 42 with 2.5 storms per season on the average; during the second one those were 67 with about 3.2 storms, respectively; and for the last sub-period data indicate 40 storms with about 2.3 storms per season on the average (Fig. 4). The above mentioned time-spans of lower storm occurrence extended for 4 seasons each - 1964-1967 and 1989-1992 with only 1-2 storms in each. While the first two stormy sub-periods were relatively dense and uniform with respect to the storm amount, the third one was quite varied with very well pronounced decreasing trend - from 6 to 1 storm per season. Actually, there were two seasons, 2006-2007 and 2008-2009, with no storms to satisfy the adopted criteria at all. These observations suggest no homogeneous negative trend in the storm amount over the studied period but rather increasing trend from the beginning of the period until the mid 1990s and opposite trend afterwards. In addition, the latter one is fifteen times more significant that the former (Fig. 4).

During the first sub-period, particularly stormy seasons were 1948-1949, 1957-1958 and 1962-1963 with 4 storms per season, while during the second one these were 19681969, 1980-1981 with 6 storms in each, but also 1971-1972, 1981-1982, 1983-1984, 1986-1987 with 4 storms. The third sub-period is described by an intense start of 4 storm seasons among which the stormiest were 1994-1995 season (6 storms) and 1997-1998 (5 storms). The second peak is marked by 2002-2003 season with 4 storms. After that a sharp fall was observed - the cause for the significant downward trend.
However, the number of storms could be misleading as it does not account for the actual storm duration and incident storm wave energy. Information on extreme values of those proxies is shown in Tables 1 and 2, revealing which were the most energetic seasons.

Roughly, values of the average wave energy are somewhat higher in the second half of the studied period, while those of the total - in the first half. It is confirmed that 1968-1969 and 1980-1981 were the stormiest seasons (in particular in terms of total proxies: 760 and 597 stormy hours, and wave energy 11 and $8.1 \times 10^{-6} \mathrm{~J} \mathrm{~m}^{-2}$, respectively). The second half of the 1970s emerged as very stormy and first half of the 1990s as well.

Actually, during 1976-1979 had occurred few of the most severe storms for 1948-2010, which appeared to be the most cited in the local scientific and grey literature (Andreeva et al., 2011). They damaged considerably the environment and engineering structures along the coast (Stakev, 1980; Trifonova et al., 2012). Storms from the beginning of the 1990s are under-studied although they marked the latest leap of storminess. Current dataset shows that the most severe was the storm of January 1981 with absolute maximum of significant wave height $10.97 \mathrm{~m}$ and wind velocity $27.6 \mathrm{~m} \mathrm{~s}^{-1}$; followed by the catastrophic storm of January 1977 and the one of December 1991. The ten most severe storms that occurred during 1948-2010 and their properties are listed in Table 3.

It was estimated that storm duration varies between $56 \mathrm{~h}(\sim 2.3$ days $)$ and $151 \mathrm{~h}(\sim 6.3$ days $)$ as the average duration is $95 \mathrm{~h}(\sim 4$ days $)$. Extreme storms have quite short growth phase, the phase of the full development is more substantial while the decay time is the longest. On the average its duration is $61 \mathrm{~h}$ and is longer than both the first and the second phases put together, which last 18 and $41 \mathrm{~h}$, respectively. Hence, the typical storm pattern is characterized with fast growth, rather durable energetic development phase and relatively prolonged decay.

Coming back to the seasonal data series, we noticed that the average storm duration and wave energy exhibit the same local trends (Fig. 5) as observed for the storm number: increase until the mid 1990s and a sharper decrease afterwards. In contrast to the storm number, however, the overall trend is positive.

This finding agrees with the WASA conclusion that there was a positive trend in the storminess from the 1960s to the 1990s and storms' intensity afterwards is comparable to that of the early twentieth century (WASA, 1998). Presence of both upward and downward trends in the storminess during the past century, with return to average calm conditions, is detected by Weisse and Günther (2007) and Matulla et al. (2008) as well.

On the other hand, the total storm duration and wave energy, while exhibiting important changes over the period, show no statistically significant overall trend (Fig. 6). The three sub-periods are still well discernable having similarity 
Table 1. The five most and the one least intensive storm seasons within the study period 1948-2010, ranked according to average and total storm duration proxies.

\begin{tabular}{|c|c|c|c|c|c|c|c|c|}
\hline \multirow[t]{4}{*}{ Rank } & \multicolumn{8}{|c|}{ Average duration $[\mathrm{h}]$} \\
\hline & \multirow{2}{*}{\multicolumn{2}{|c|}{ Storms }} & \multicolumn{6}{|c|}{ Storm phases } \\
\hline & & & \multicolumn{2}{|c|}{ I } & \multicolumn{2}{|c|}{ II } & \multicolumn{2}{|c|}{ III } \\
\hline & season & value & season & value & season & value & season & value \\
\hline 1 & 04_05 & 151 & 00_01 & 52 & 04_05 & 86 & 85_86 & 87 \\
\hline 2 & $85 \_86$ & 147 & $59 \_60$ & 37 & 92_93 & 71 & 71_72 & 68 \\
\hline 3 & $71 \_72$ & 146 & $51 \_52$ & 35 & $64 \_65$ & 70 & 74_75 & 63 \\
\hline 4 & 78_79 & 134 & 89_90 & 34 & 78_79 & 68 & 04_05 & 56 \\
\hline 5 & $76 \_77$ & 128 & 84_85 & 30 & 76_77 & 65 & 49_50 & 55 \\
\hline $\min$ & 03_04 & 56 & 03_04 & 8 & $50 \_51$ & 17 & 03_04 & 20 \\
\hline Rank & \multicolumn{8}{|c|}{ Total duration $[\mathrm{h}]$} \\
\hline 1 & $68 \_69$ & 760 & $68 \_69$ & 154 & $68 \_69$ & 364 & $71 \_72$ & 271 \\
\hline 2 & $80 \_81$ & 597 & 59_60 & 110 & 80_81 & 303 & $68 \_69$ & 242 \\
\hline 3 & 71_72 & 583 & 02_03 & 106 & 71_72 & 228 & 80_81 & 205 \\
\hline 4 & 93_94 & 432 & 94_95 & 94 & 78_79 & 204 & 94_95 & 189 \\
\hline 5 & 94_95 & 423 & 97_98 & 91 & 76_77 & 194 & 85_86 & 174 \\
\hline $\min$ & 56_57 & 59 & 04_05 & 9 & 50_51 & 17 & 82_83 & 20 \\
\hline
\end{tabular}

Table 2. The five most and the one least intensive storm seasons within the study period 1948-2010, ranked according to average and total values of the wave energy proxies.

\begin{tabular}{|c|c|c|c|c|c|c|c|c|}
\hline \multirow[t]{4}{*}{ Rank } & \multicolumn{8}{|c|}{ Average wave energy $\left[\times 10^{-6}\left[\mathrm{~J} \mathrm{~m}^{-2}\right]\right]$} \\
\hline & \multirow{2}{*}{\multicolumn{2}{|c|}{ Storms }} & \multicolumn{6}{|c|}{ Storm phases } \\
\hline & & & \multicolumn{2}{|c|}{ I } & \multicolumn{2}{|c|}{ II } & \multicolumn{2}{|c|}{ III } \\
\hline & season & value & season & value & season & value & season & value \\
\hline 1 & 76_77 & 2.19 & 00_01 & 0.24 & 76_77 & 1.80 & 85_86 & 0.54 \\
\hline 2 & $68 \_69$ & 1.83 & 51_52 & 0.21 & 91_92 & 1.60 & 71_72 & 0.41 \\
\hline 3 & 91_92 & 1.80 & 59_60 & 0.20 & 96_97 & 1.56 & 04_05 & 0.40 \\
\hline 4 & 96_97 & 1.79 & 89_90 & 0.17 & 92_93 & 1.46 & 49_50 & 0.38 \\
\hline 5 & 04_05 & 1.75 & 98_99 & 0.14 & 68_69 & 1.38 & 09_10 & 0.33 \\
\hline $\min$ & $82 \_83$ & 0.46 & 05_06 & 0.02 & 00_01 & 0.27 & 82_83 & 0.09 \\
\hline Rank & \multicolumn{8}{|c|}{ Total wave energy $\left[\times 10^{-6}\left[\mathrm{~J} \mathrm{~m}^{-2}\right]\right]$} \\
\hline 1 & $68 \_69$ & 10.99 & $68 \_69$ & 0.82 & 68_69 & 8.25 & $68 \_69$ & 1.91 \\
\hline 2 & 80_81 & 8.09 & 59_60 & 0.60 & 80_81 & 6.51 & 71_72 & 1.66 \\
\hline 3 & 76_77 & 6.57 & 80_81 & 0.46 & 76_77 & 5.39 & 94_95 & 1.24 \\
\hline 4 & 71_72 & 5.96 & $71 \_72$ & 0.44 & 93_94 & 4.33 & 49_50 & 1.15 \\
\hline 5 & 93_94 & 5.63 & 70_71 & 0.42 & 97_98 & 4.04 & 80_81 & 1.12 \\
\hline $\min$ & $82 \_83$ & 0.46 & 04_05 & 0.02 & 00_01 & 0.27 & $82 \_83$ & 0.09 \\
\hline
\end{tabular}

to the average proxies' relative intensity. However, when examining the LPF approximation, a stepwise decreasing trend becomes evident within each sub-period. It is observed that generally every sub-period consists of three time-spans of 7 to $9 \mathrm{yr}$ of duration, as each succeeding local maximum gradually decreases toward the end of the sub-period. These maxima coincide with very cold winters in eastern Bulgaria (Tishkov, 1991). The first maximum in the sub-period 
Table 3. The ten most severe storms that occurred during 1948-2010, ranked according to significant wave height maxima, and their properties; SWH - significant wave height, WV - wind velocity, $E_{\mathrm{spf}}-$ specific wave energy.

\begin{tabular}{|c|c|c|c|c|c|c|c|c|c|}
\hline \multirow[t]{2}{*}{ Storm } & \multirow[t]{2}{*}{ Max SWH $[\mathrm{m}]$} & \multirow[t]{2}{*}{$\operatorname{Max} \mathrm{WV}\left[\mathrm{m} \mathrm{s}^{-1}\right]$} & \multicolumn{3}{|c|}{ Duration of storm phases $[\mathrm{h}]$} & \multicolumn{3}{|c|}{ Energy of storm phases $\times 10^{-6}\left[\mathrm{~J} \mathrm{~m}^{-2}\right]$} & \multirow[t]{2}{*}{$E_{\mathrm{spf}}$} \\
\hline & & & I & II & III & I & II & III & \\
\hline Jan 1981 & 10.97 & 27.2 & 13 & 66 & 21 & 0.14 & 3.11 & 0.11 & 336 \\
\hline Jan 1977 & 10.81 & 24.3 & 24 & 58 & 27 & 0.12 & 2.74 & 0.26 & 263 \\
\hline Dec 1991 & 10.57 & 27.6 & 12 & 94 & 54 & 0.04 & 2.94 & 0.24 & 126 \\
\hline Jan 2004 & 9.68 & 27.8 & 7 & 36 & 15 & 0.02 & 1.16 & 0.09 & 379 \\
\hline Dec 1961 & 9.56 & 26.3 & 13 & 51 & 25 & 0.05 & 1.44 & 0.09 & 200 \\
\hline Feb 1954 & 9.51 & 25.2 & 21 & 48 & 34 & 0.09 & 1.32 & 0.31 & 162 \\
\hline Dec 1997 & 9.5 & 23.2 & 10 & 60 & 34 & 0.04 & 2.16 & 0.19 & 221 \\
\hline Jan 1969 & 9.46 & 24.7 & 28 & 78 & 37 & 0.29 & 2.65 & 0.42 & 164 \\
\hline Feb 1979 & 9.36 & 21.8 & 24 & 119 & 47 & 0.12 & 2.85 & 0.19 & 88 \\
\hline Dec 1996 & 9.17 & 25 & 12 & 72 & 26 & 0.08 & 2.82 & 0.19 & 255 \\
\hline
\end{tabular}
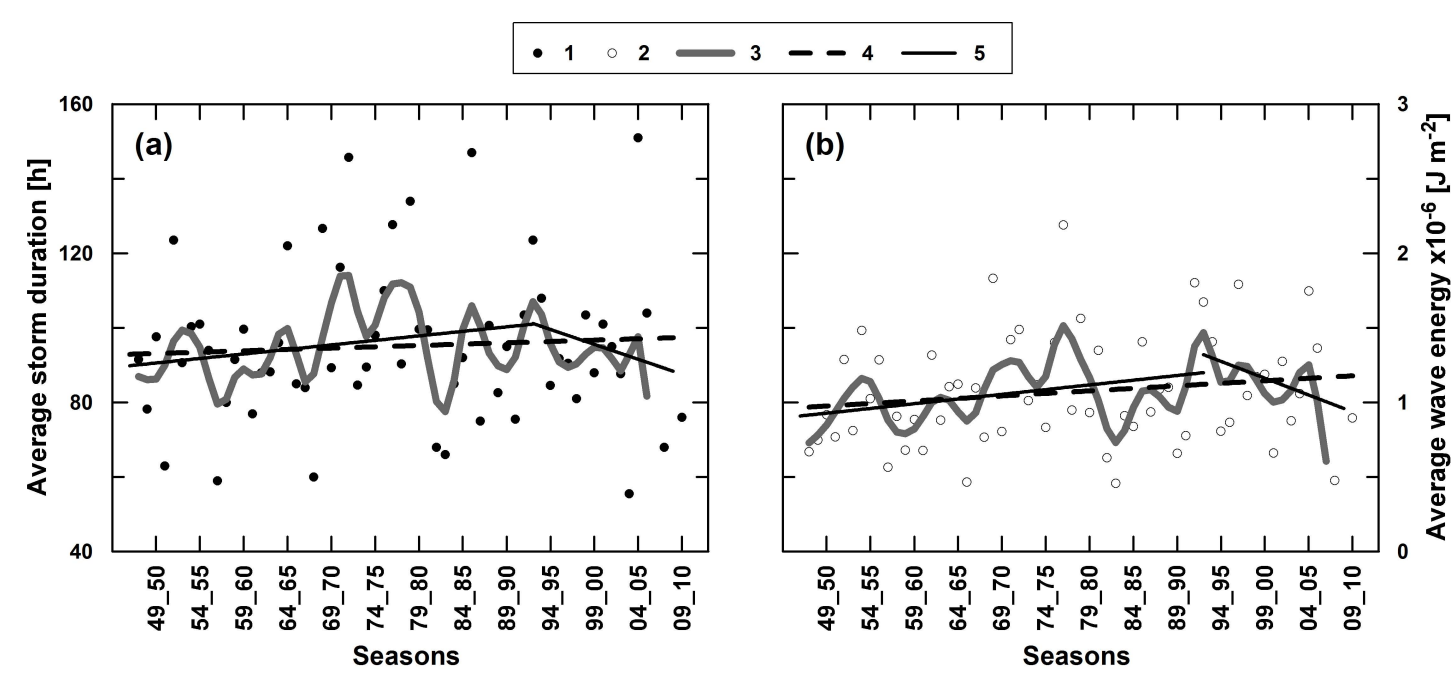

Fig. 5. Variability of average storm duration and average wave energy during 1948-2010; (a) average storm duration: 1 - data points, 3 - LPF approximation, $4-$ global linear trend $\left(0.072 \mathrm{hdecade}^{-1}, R^{2}=0.003\right), 5-$ local linear trends - upward $\left(2.4 \mathrm{~h}\right.$ decade ${ }^{-1}$, $\left.R^{2}=0.024\right)$, downward ( $\left.8 \mathrm{~h} \mathrm{decade}^{-1}, R^{2}=0.027\right)$; (b) average wave energy: 2 - data points, 3 - LPF approximation, $4-$ global linear trend $\left(0.034 \times 10^{-6} \mathrm{~J} \mathrm{~m}^{-2} \mathrm{decade}^{-1}, R^{2}=0.03\right), 5$ - local linear trends - upward $\left(0.063 \times 10^{-6} \mathrm{~J} \mathrm{~m}^{-2} \mathrm{decade}^{-1}, R^{2}=0.05\right)$, downward $\left(0.23 \times 10^{-6} \mathrm{~J} \mathrm{~m}^{-2}\right.$ decade $\left.^{-1}, R^{2}=0.07\right)$.

that stretched up to 1964, which is not present in the dataset, was presumably the largest. It probably corresponds to the winter of 1942 , which was reported to be the coldest one during 1899-1988. In case that this assumption is plausible, another time-span of low storminess could be expected in the next decade. Such hypothesis could explain the drop in storm intensity at the end of the studied period. However, the magnitude of the drop is larger than could be expected, and suggests occurrence of either climate disturbance or variability on time scale larger than the time-span of the available dataset. It should be mentioned that exceptionally severe winter storms were likely to happen during the climatic cooling phase known as Little Ice Age, which occurred from the middle of the 15th century to the 19th century (Lamb, 1979; Budillon et al., 2006).

According to the total proxies, the largest amount of wave energy was observed during the second half of the 1960s and in the 1980s. The result supports to a certain extent the conclusion about the average proxies, in particular the growth of storm intensity in the first half of the studied period.

Additionally, the variability of storm intensity is assessed in terms of the average maximum and average mean calculated over the most energetic part of the storm wind velocity and significant wave height. These data show a trend of gradual increase without any considerable falls, which is obvious for the wind velocity series in particular (Fig. 7a, b). There is 


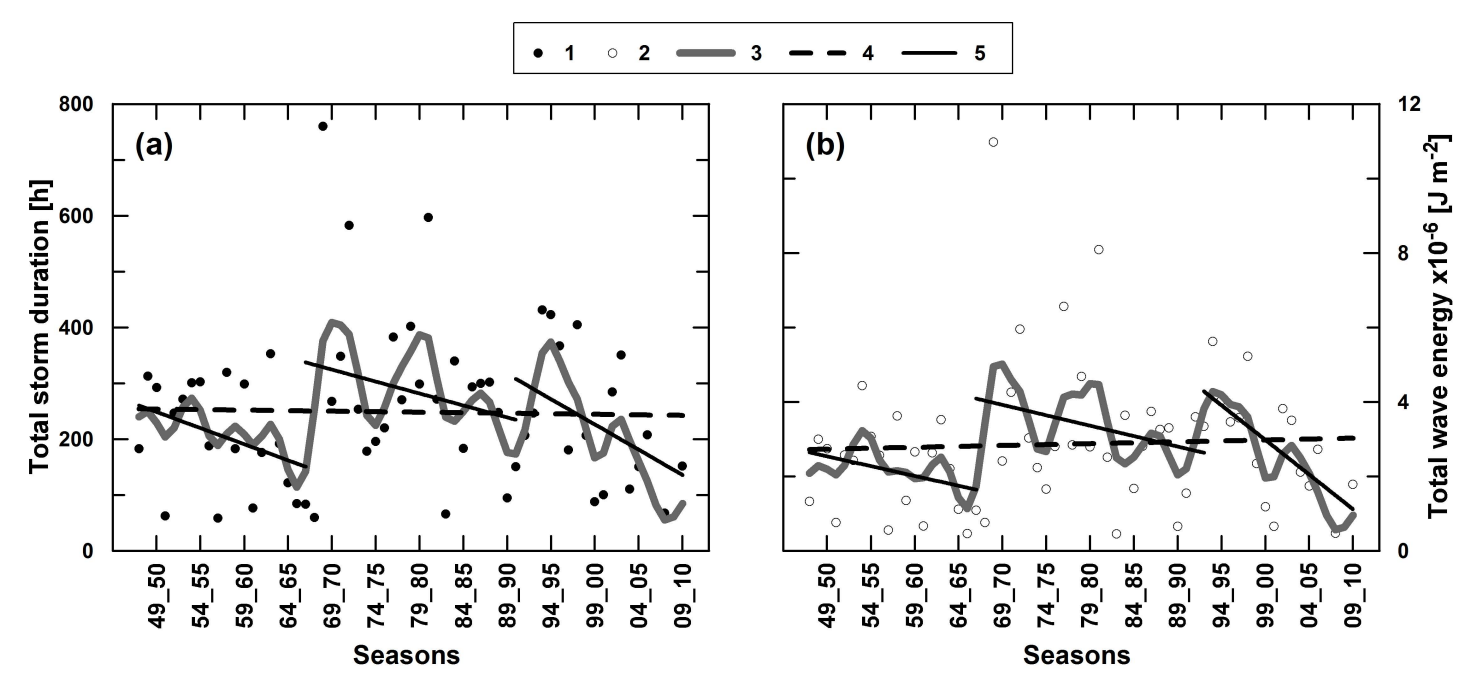

Fig. 6. Variability of the total storm duration and wave energy during 1948-2010; (a) Total storm duration: 1 - data points, 3 - LPF approximation, $4-$ global linear trend $\left(-1.9 \mathrm{~h} \mathrm{decade}^{-1}, R^{2}=0.0006\right), 5-$ local downward linear trends $\left(\mathrm{I}\right.$ sub-period $-57.8 \mathrm{~h}$ decade ${ }^{-1}$, $R^{2}=0.12$; II sub-period $-42.8 \mathrm{~h}$ decade ${ }^{-1}, R^{2}=0.035$; III sub-period $-90.4 \mathrm{~h} \mathrm{decade}^{-1}, R^{2}=0.18$ ); (b) Total wave energy: $2-$ data points, 3 - LPF approximation, 4 - global linear trend $\left(0.05 \times 10^{-6} \mathrm{~J} \mathrm{~m}^{-2}\right.$ decade $\left.^{-1}, R^{2}=0.18\right)$, 5-local downward linear trends (I sub-period $-0.53 \times 10^{-6} \mathrm{~J} \mathrm{~m}^{-2}$ decade $^{-1}, R^{2}=0.12$; II sub-period $-0.56 \times 10^{-6} \mathrm{~J} \mathrm{~m}^{-2}$ decade $^{-1}, R^{2}=0.037$; III sub-period $\left.1.86 \times 10^{-6} \mathrm{~J} \mathrm{~m}^{-2} \mathrm{decade}^{-1}, R^{2}=0.4\right)$.

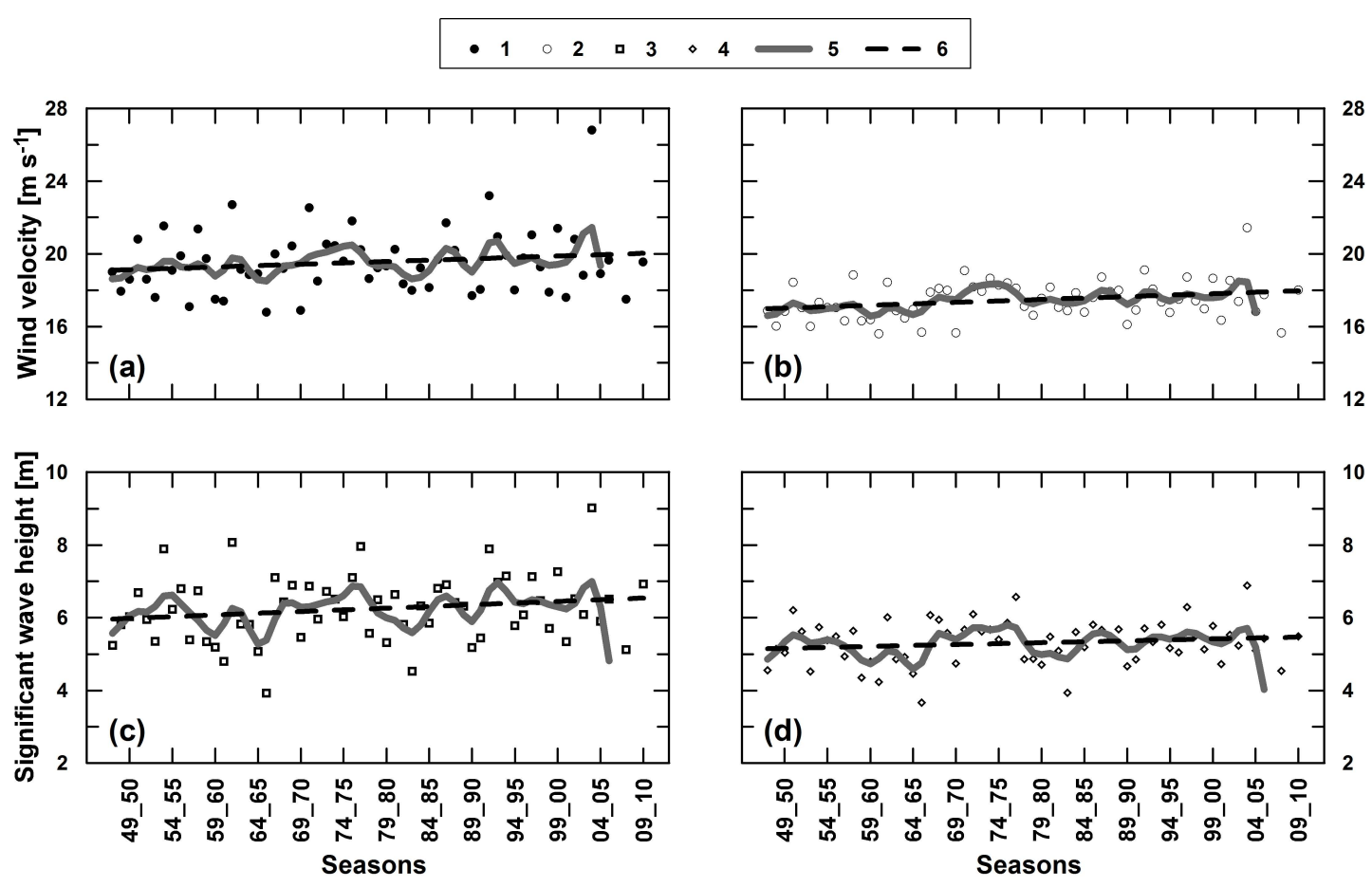

Fig. 7. Variability of average maximum and average mean over the storms' second phase values of wind velocity and significant wave height during 1948-2010; (a) average maximum wind velocity: 1 - data points, 5 - LPF approximation, 6 - global linear trend $\left(0.15 \mathrm{~m} \mathrm{~s}^{-1}\right.$ decade $\left.^{-1}, R^{2}=0.023\right)$; (b) average mean wind velocity of the II phase: 2 - data points, 5 - LPF approximation, 6 - global linear trend $\left(0.16 \mathrm{~m} \mathrm{~s}^{-1}\right.$ decade $\left.{ }^{-1}, R^{2}=0.071\right)$; (c) average maximum significant wave height: 3 - data points, 5 - LPF approximation, 6 - global linear trend $\left(0.09 \mathrm{~m}\right.$ decade $\left.{ }^{-1}, R^{2}=0.032\right)$; (d) average mean significant wave height of the II phase: $4-$ data points, $5-$ LPF approximation, 6 - global linear trend $\left(0.05 \mathrm{~m} \mathrm{decade}^{-1}, R^{2}=0.022\right)$. 


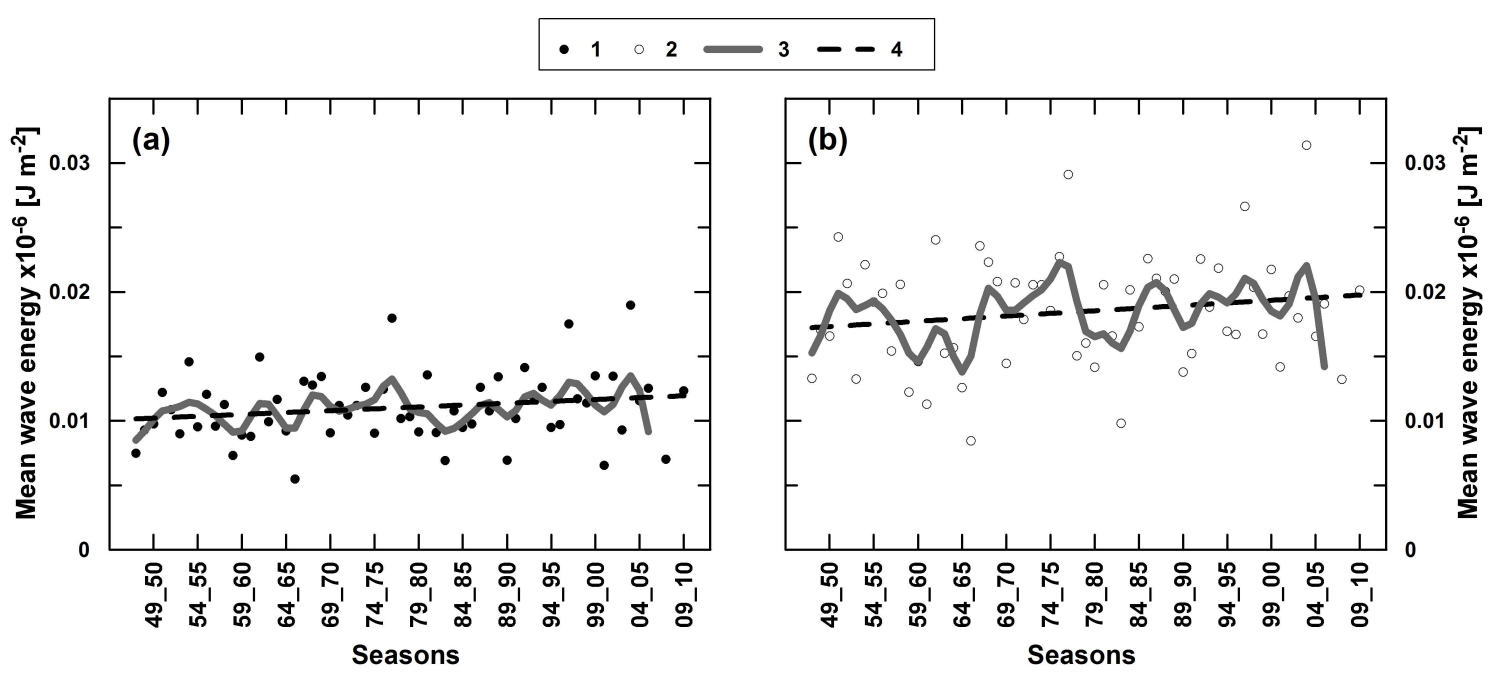

Fig. 8. Variability of mean wave energy during 1948-2010; (a) for the entire storm duration: 1 - data points, 3 - LPF approximation, 4 global linear trend $\left(28.9 \times 10^{-6} \mathrm{~J} \mathrm{~m}^{-2} \mathrm{decade}^{-1}, R^{2}=0.04\right)$; (b) for the storms' second phase: $2-$ data points, 3 - LPF approximation, $4-$ global linear trend $\left(40.7 \times 10^{-6} \mathrm{~J} \mathrm{~m}^{-2}\right.$ decade $\left.^{-1}, R^{2}=0.03\right)$.

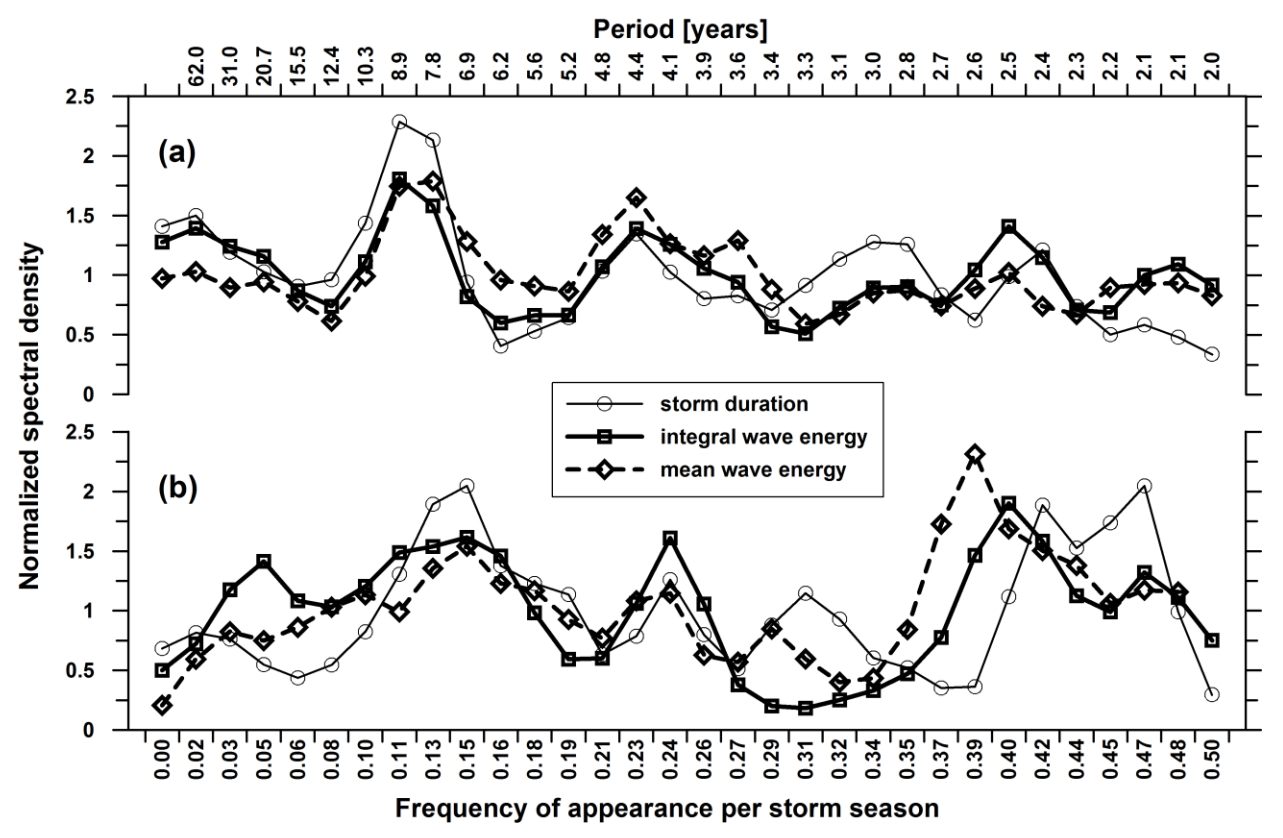

Fig. 9. Normalized spectral density of total (a) and average (b) proxies.

a difference between maximum and mean wave height series' trends, though: if not well pronounced increase, the former suggests at least a steady upward trend (Fig. 7c), while the latter demonstrates rather a decrease after the 1970s (Fig. 7d). This result is consistent with the global total wave energy trend.

As for the mean storm wave energy, again a positive trend is observed (Fig. 8) similar to that of the wave height (Fig. 7). The figure depicts average mean energy of the storm as a whole and only of the most energetic second phase. No sig- nificant distinction between trends can be detected except for the storms' second phase appears to be more important.

The results shown in Figs. 7-8 are very similar, but representing the storminess by the mean wave energy rather than mean wave height makes the contribution of severe storms more explicit. 


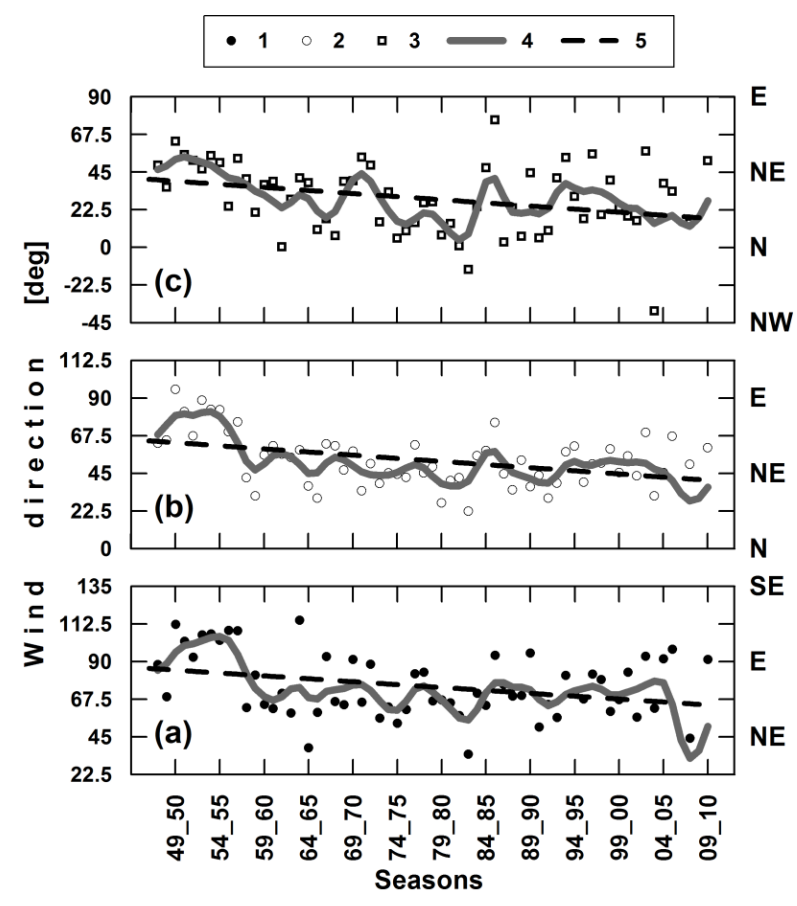

Fig. 10. Variability of average wind direction for each of the storm phases during 1948-2010. Downward trend indicates northward shift of prevailing wind direction; (a) growth phase: 1 - data points, 4 - LPF approximation, 5 - global linear trend (3.5 deg decade ${ }^{-1}$, $\left.R^{2}=0.103\right)$, (b) developed sea phase: 2 - data points, $4-$ LPF approximation, 5 - global linear trend $\left(3.75 \mathrm{deg}_{\text {decade }}{ }^{-1}, R^{2}=\right.$ $0.17)$, (c) decay phase: 3 - data points, 4 - LPF approximation, 5 global linear trend (3.71 deg decade ${ }^{-1}, R^{2}=0.096$ ).

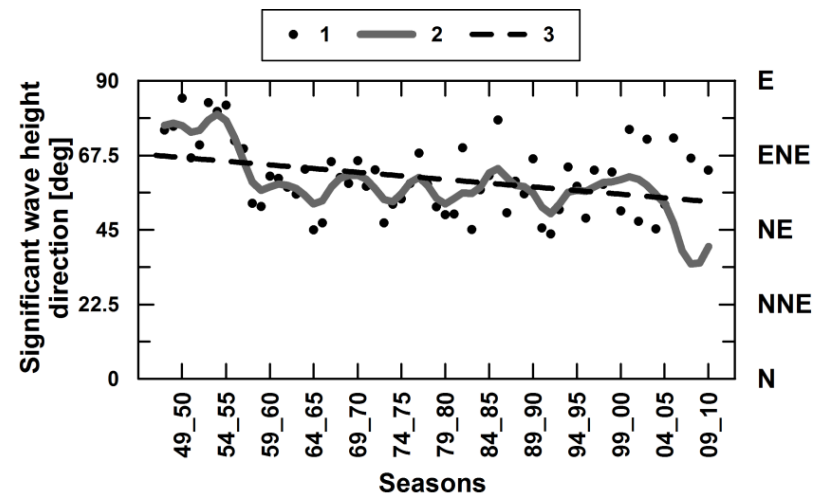

Fig. 11. Variability of average direction of wave propagation during 1948-2010. Downward trend indicates northward shift in the predominant wave direction; 1 - data points, 2 - LPF approximation, 3 - global linear trend $\left(2.21\right.$ deg decade $\left.^{-1}, R^{2}=0.13\right)$.

\section{Discussion}

Proxies described in the previous section do not assert a significant trend in storminess. Although, both upward and downward trends were detected none of them appear to be steady. This is probably due to the dominance of short-term fluctuations over any potential longer-term signal. Several studies (e.g. Schmith, 1995; WASA Group, 1998; Weisse et al., 2005; Lozano et al., 2004; Matulla et al., 2008) found that significant alterations on a quasi-decadal timescale were present in Europe's cyclonic activity and associated storm climate. In order to check the validity of this statement for the western Black Sea, spectral analysis of the total and average proxies' seasonal series was performed. Results for storm duration, integral and mean wave energy are presented in Fig. 9. Normalized spectral density of each proxy was obtained by its division by the corresponding mean.

It can be seen that the total proxies' absolute spectral density maximum is observed for $8.9 \mathrm{yr}$ time period. This maximum for the average proxies is shifted towards the shorter period of $7.8 \mathrm{yr}$, which is however only a local one. The absolute maximum of the average proxies' spectral density appears at much shorter time periods, that is 2.1-2.6 yr. Both series have well pronounced local maxima at $4.4 \mathrm{yr}$. Clearly, the considered period is not sufficiently long to detect a larger scale signal. Thus, the predominant time scale of proxies' variations is quasi-decadal. The result complies with overall European tendency.

Furthermore, it seems that the observed storm proxies' long-term behavior is rather contradictory. The decrease in duration and subsequently in the total amount of wave energy is evident but, on the other hand, there is a slight positive trend in the average proxies (at least until the last decade of the 20th century) particularly visible in the mean wind velocity and mean wave energy seasonal series. Is it possible for such a complex situation to result from a change in the storm pattern due to a shift in prevailing direction of wind action? To answer this question we examined average wind direction in each storm phase. Results are shown in Fig. 10.

Evidently, a steady trend for gradual shift of wind direction northward was found in each of the storm phases. The direction during the growth changed from ESE to ENE, during the developed sea - from $\mathrm{E}$ to NE, and during the decay - from NE to NNE and even to sheer north.

In agreement with this tendency, it was found that during the latest decades more heavy seas propagating from northeast occurred in comparison with the beginning of the period (Fig. 11). This phenomenon can be explained with refraction, which wave field starts experiencing earlier in the course of a storm due to the more rapid shift of wind direction.

The described process should have given reflection on the storm phases' duration and their wave energy. In fact, detailed examination revealed that the extreme storm pattern had altered. Whereas the duration of the first and the second 


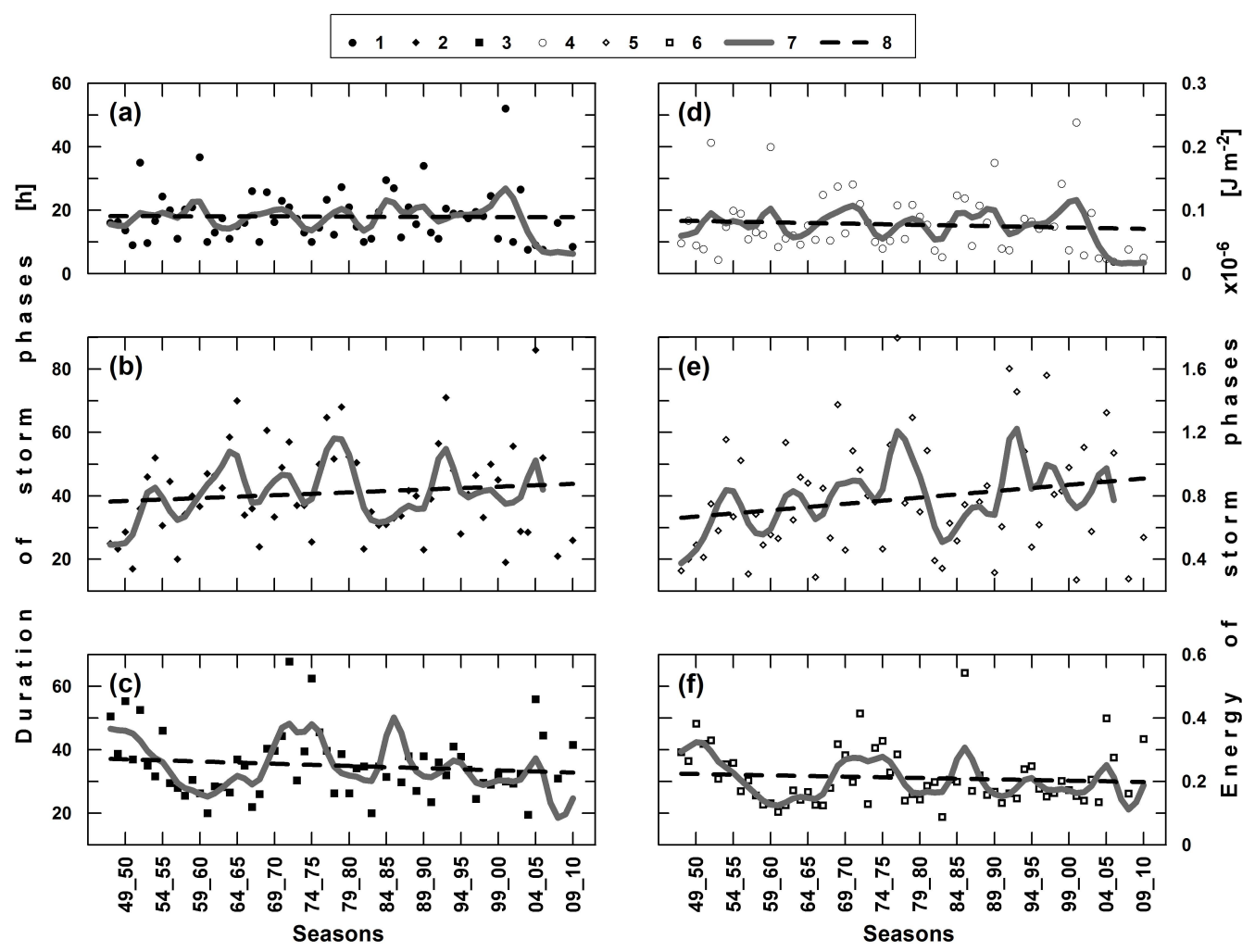

Fig. 12. Variability of average duration and wave energy of storm phases during 1948-2010; (a) Growth phase duration: 1 - data points, 7 LPF approximation, 8 - global linear trend $\left(-0.05 \mathrm{~h} \mathrm{decade}^{-1}, R^{2}=0.0002\right)$; (b) Duration of the developed sea phase: $2-$ data points, $7-$ LPF approximation, 8 - global linear trend $\left(0.9 \mathrm{~h} \mathrm{decade}^{-1}, R^{2}=0.012\right)$; (c) Decay phase duration: 3 - data points, 7 - LPF approximation, 8 - global linear trend $\left(-0.7 \mathrm{~h}_{\text {decade }}-1, R^{2}=0.016\right)$; (d) Growth phase wave energy: 4 - data points, 7 - LPF approximation, $8-$ global linear trend $\left(0.002 \times 10^{-6} \mathrm{~J} \mathrm{~m}^{-2}\right.$ decade $^{-1}$ no trend, $\left.R^{2}=0.006\right)$; (e) Wave energy of the developed sea phase: $5-$ data points, $7-\mathrm{LPF}$ approximation, 8 - global linear trend $\left(0.04 \times 10^{-6} \mathrm{~J} \mathrm{~m}^{-2} \mathrm{decade}^{-1}, R^{2}=0.04\right)$; (f) Decay phase wave energy: $6-$ data points, $7-\mathrm{LPF}$ approximation, 8 - global linear trend $\left(0.004 \times 10^{-6} \mathrm{~J} \mathrm{~m}^{-2}\right.$ decade $\left.^{-1}, R^{2}=0.007\right)$.

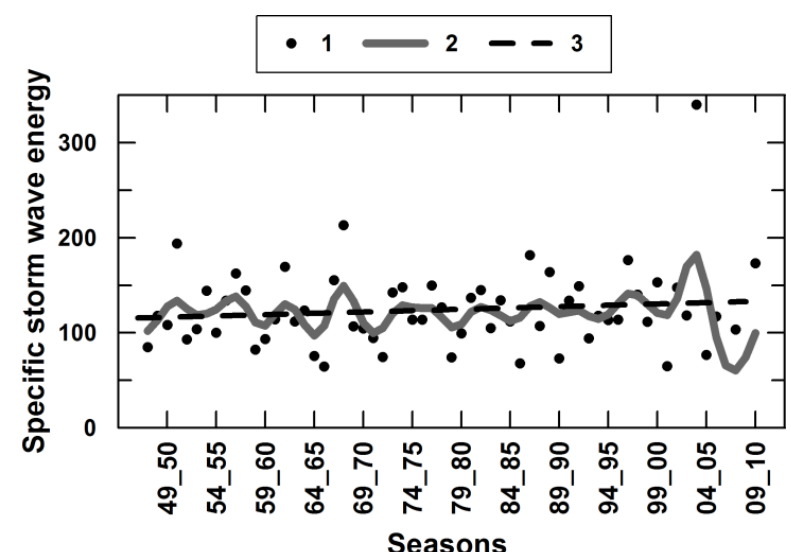

Fig. 13. Variability of specific storm energy during 1948-2010: 1 - data points, 2 - LPF approximation, 3 - global linear trend $\left(2.8 \times 10^{-6} \mathrm{~J} \mathrm{~m}^{-2} \mathrm{decade}^{-1}, R^{2}=0.013\right)$. phase has undergone weak long-term changes in general almost no change for the growth (Fig. 12 a) and slight increase for the developed sea (Fig. 12 b) are observed - the negative trend for the decay phase duration has been quite important (Fig. 12 c). This is markedly valid after the 1980s. The same trends but for the wave energy are even more pronounced (Fig. 12 e, f).

It is ascertained that rapidly decaying storms occurred more often during the second half of the studied period, which explains the augmentation of the average integral and mean storm wave energy in statistical sense (Fig. 8). Moreover, even if the duration had decreased as a whole, the intensity of the storms' most energetic part remained high.

The above finding was corroborated by the long-term behavior of the last proxy to be discussed in this paper, namely specific storm energy. The variability of $E_{\mathrm{spf}}$ is presented in Fig. 13 and shows a well defined positive trend. It implies that the storm wave energy augmented throughout the studied period, mainly due to the combined effect of shortened storm duration and increase of the wave energy of the second storm phase. Results are similar to those obtained 


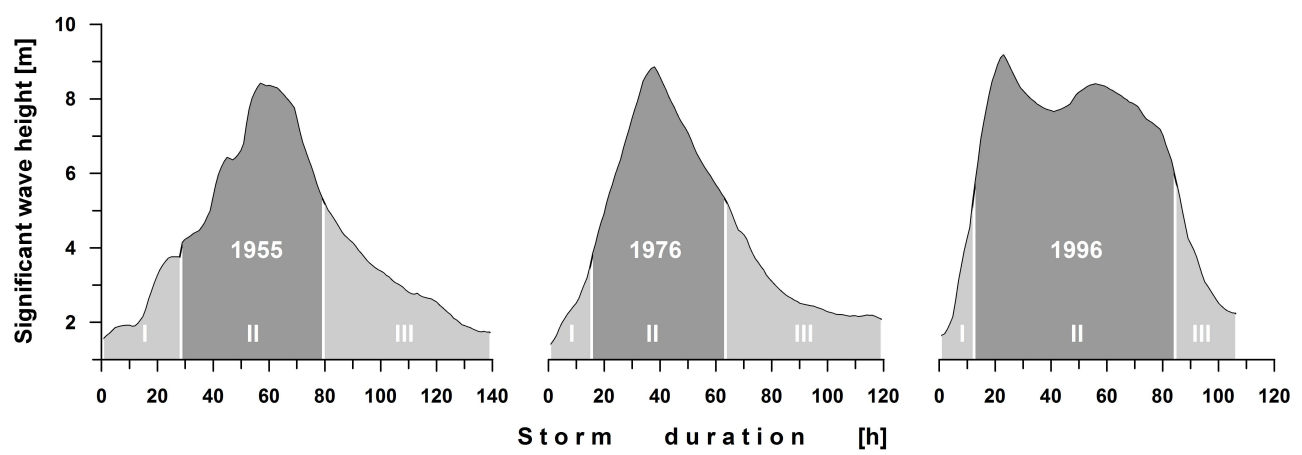

Fig. 14. Alteration in the storm pattern on the example of storms that occurred in February 1955, February 1976 and December 1996.

for instance by Dolan et al. (1989) who analysed all storms considered as damaging for the coastal areas in the western Atlantic, and discovered shortening of the average storm duration, possibly due to a shift of the mean winter storm track to more northern latitudes. Clearly, the cause for wind direction shift in the Black Sea should be sought in an analogous phenomenon.

An illustration of the storm pattern alteration is presented in Fig. 14 on the example of three of the most significant storms that occurred during 1948-2010: February 1955, February 1976 and December 1996. Thus, contemporary storms hitting the western Black Sea coasts do not seem to become less hazardous than those occurring in the middle of the studied period.

Finally, we will discuss our results in light of the NAO influence on the European and regional climate patterns. A negative correlation was found to exist between the NAO index and cyclones' characteristics in January-March, supporting the understanding for mechanism through which the NAO contributes to regulation of European climate anomalies, including the Mediterranean-Black Sea region (Polonsky et al., 2004). Voskresenskaya and Maslova (2011) reported that for the Black Sea region, the correlation between the NAO index and frequency of cyclones is more significant with respect to their depth and area. According to the mentioned study, the NAO controls $28 \%$ of the cyclone frequency and 15-20\% of their depth and area variability.

Winter cyclones in the Mediterranean-Black Sea region demonstrate pronounced decadal variability, which is out-ofphase with the NAO (Bardin and Polonsky, 2005; Lionello et al., 2006). Moreover, in correlation with the low-frequency NAO mode, a decrease in the cyclonic activity in the region since the late 1960 s was traced on a several decades timescale (Polonsky, 2004). This finding is in agreement with the decrease in the number of storms indicated in the present study, as well as, with results reported by Lozano et al. (2004) for the Atlantic margin of Europe.

The effect of the sea surface temperature (SST) on the intensity of mid-latitude cyclones was demonstrated, for in- stance by Enfield and Mestas-Nuñez (1999) and Giordani and Caniaux (2001). The climatic signal related to the SST anomaly over the North Atlantic and an analogue of the multidecadal NAO mode is the AMO. Similarly to the NAO, it is characterized by a shift of the North Atlantic storm tracks but with the opposite sign (e.g. Polonsky, 2011). During the positive NAO phase the Icelandic Low and Azores High are typically shifted to the northeast, while during the positive AMO phase - to the southwest. Associated trajectories of North Atlantic cyclones shift to Northern Europe or to Southern Europe and the Mediterranean-Black Sea region. According to a still unpublished study (Polonsky et al., 2012), the influence of SST on characteristics of synoptic systems in the Mediterranean-Black Sea is detectable and can be associated with the AMO. An agreement is found between proxies' interdecadal variability examined in the present study and SST in the northeastern Black Sea (Polonsky et al., 2012). More specifically, periods of increased storminess in the western Black Sea can be associated with a decrease of SST: 19501960, 1970-1980 and 1985-1995.

\section{Conclusions}

The study investigated trends in the past and more recent storminess over the western Black Sea, thus complementing studies on the European storminess arriving at similar conclusions. Model hindcast database spanning 63 storm seasons was used to create a storm population and to estimate a number of average and total storminess proxies. Eleven proxies were obtained for each storm season and their long-term variability was carefully examined in order to reveal possible trends. While some trends suggest increase of storminess until the 1990s and sharp decrease afterwards, others indicate upward trend only until the 1980s and/or disclose rather complex interdecadal variability, which, however, do not affect considerably the overall trend. In general, none of the identified trends support an assertion of either significant increase or decrease in storminess. The decrease in duration and subsequently in the total amount of wave energy is apparent, but 
on the other hand, there is a positive trend in the average proxies that is particularly valid for the mean wind velocity and mean wave energy seasonal series. However, the most recent years are characterized by a return to average or even calm conditions. Proxies' interannual-to-interdecadal variability was found to correlate with the phases of the NAO and AMO indices.

Results showed a shortening of the average duration of storms. This could be attributed mainly to curtail of the decay storm phase possibly due to a shift of prevailing direction of storm forcing winds to the north. Nevertheless, even if the total duration had diminished, the intensity of the storms' most energetic part remained high but yet growing. These circumstances cause a change in the storm pattern: rapidly decaying storms occurred more often during the second half of the studied period. This storm type still provides significant energy input in the coastal areas and is able of producing considerable damage.

Despite of the pronounced downward trend after the 1990s, there are no incontestable proofs for a marked reduction in the storm intensity. Hence, lessening of vulnerability to storms in the western Black Sea is unlike. This means the society should take into consideration such far-reaching implications while planning strategies for coastal development and disaster mitigation activities.

Acknowledgements. This research has received funding from the European Community's Seventh Framework Programme under grant agreement no. 202798 (MICORE Project).

Edited by: P. Ciavola

Reviewed by: two anonymous referees

\section{References}

Andreeva, N., Valchev, N., Trifonova, E., Eftimova, P., Kirilova, D., and Georgieva, M.: Literary review of historical storm events in the western Black Sea, Proc. of Union of Scientists - Varna, Marine Sciences, 105-112, 2011 (in Bulgarian).

Bacon, S. and Carter, D. J. T: Wave climate changes in the North Atlantic and North Sea, Int. J. Climatol., 11, 545-558, 1991.

Balev, I.: Distribution of the population by regions, municipalities, towns and villages, 1, National Statistical Institute, Sofia, Bulgaria, 253 pp., 2002 (in Bulgarian).

Bardin, M. Yu. and Polonsky, A. B.: North Atlantic Oscillation and synoptic variability in the European-Atlantic region in winter, Izv. Atmos. Ocean. Phys., 41, 127-136, 2005.

Belberov, Z., Davidan, I., Kostichkova, D., Lavrenov, I., Lopatukhin, L., and Cherneva, Zh.: Main principles for creation of a new wind-wave atlas of the Bulgarian sector of the Black Sea, Proceedings of IO-BAS, Varna, 1, 5-12, 1992 (in Bulgarian).

Berek, E. P., Cardone, V. J., and Swail, V. R.: Comparison of hindcast results and extreme value estimates for wave conditions in the Hibernia area - Grand Banks of Newfoundland, 6th International Workshop on Wave Hindcasting and Forecasting November 6-10, 2000, Monterey, California, 2000.
Booij, N., Ris, R. C., and Holthuijsen, L. H.: A third-generation wave model for coastal regions, Part I, Model description and validation, J. Geophys. Res., 104, C4, 7649-7666, 1999.

Budillon, F., Vicinanza, D., Ferrante, V., and Iorio, M.: Sediment transport and deposition during extreme sea storm events at the Salerno Bay (Tyrrhenian Sea): comparison of field data with numerical model results, Nat. Hazards Earth Syst. Sci., 6, 839-852, doi:10.5194/nhess-6-839-2006, 2006.

Cardone, V., Jensen, R., Resio, T., Swail, V., and Cox, A.: Evaluation of contemporary ocean wave models in rare extreme events: The "Halloween Storm" of October 1991 and the "Storm of the Century" of March 1993, J. Atmos. Ocean. Tech., 13, 198-230, 1996.

Carter, D. J. T. and Draper, L.: Has the northeast Atlantic become rougher?, Nature 332, 494, doi:10.1038/332494a0, 1988.

Cherneva, Z., Andreeva, N., Pilar, P., Valchev, N., Petrova, P., and Soares, C. G.: Validation of the WAMC4 model for the Black Sea, Coast. Eng., 55, 881-893, 2008.

Cooper, J. A. G., Jackson, D. W. T., Navas, F., McKenna, J., and Malvarez, G.: Identifying storm impacts on an embayed, highenergy coastline: western Ireland, Mar. Geol., 210, 261-280, 2004.

Davidan, I. N.: Problems of investigation and mathematical modeling of wind waves, Gidrometeoizdat, St. Petersburg, 472 pp., 1995 (in Russian).

Davidan, I., Valchev, N., Belberov, Z., and Valcheva, N.: Assessment of the reanalysed wind field accurateness for wave modelling purposes in the Black Sea region, Proc. Int. Conf.: EuroGOOS - European Operational Oceanography: Present and Future, Brest, France, 801-805, 2006.

Dolan, R., Lins, H., and Hayden, B.: Mid-Atlantic coastal storms, J. Coast. Res., 4, 417-433, 1989.

Duffy, M. J and Devoy, R. J. N.: Contemporary process controls on the evolution of sedimentary coasts under low to high-energy regimes: western Ireland, Geologie Mijnbouw, 77, 333-349, 1999.

Enfield, D. and Mestas-Nuñez, A. M.: Multiscale variability in global SST and their relationships with tropospheric climate patterns, J. Climate, 9, 2719-2733, 1999.

Ferreira, Ó., Ciavola, P., Armaroli, C., Balouin, Y., Benavente, J., Del Río, L., Deserti, M., Esteves, L.S., Furmanczyk, K., Haerens, P.,Matias, A., Perini, L., Taborda, R., Terefenko, P., Trifonova, E., Trouw, K., Valchev, N., Van Dongeren, A., Van Koningsveld, M. and Williams, J.J.: Coastal Storm Risk Assessment in Europe: Examples from 9 study sites, SI 56 (Proceedings of the 10th International Coastal Symposium), Lisbon, Portugal 1632-1636, 2009.

Feser, F., Weisse, R., and von Storch, H.: Multidecadal atmospheric modelling for Europe yields multi-purpose data, EOS, 82, 305310, 2001.

Giordani, H. and Caniaux, G.: Sensitivity of Cyclogenesis to Sea Surface Temperature in the North Western Atlantic, Mon. Weather Rev., 129, 1273-1295, 2001.

Guide to wave analysis and forecasting, WMO-No.702, 159 pp., 1992.

Gulev, S. K., Grigorieva, V., Sterl, A., and Woolf, D.: Assessment of the reliability of wave observations from voluntary observing ships: insights from the validation of a global wind wave climatology based on voluntary observing ship data, J. Geophys. Res., 
108, 3236, doi:10.1029/2002JC001437, 2003.

Günther, H., Hasselmann, S., and Janssen, P. A. E. M.: Wave model Cycle 4, Technical Report No.4, Deutsches Klima Rechen Zentrum, Germany, 1992.

Hurrell, J. W. and van Loon, H.: Decadal variations in climate associated with the North Atlantic Oscillation, Climate Change, 36, 301-326, doi:10.1023/A:1005314315270, 1997.

Jeffrey, C. R.: North Atlantic Storm Track Variability and Its Association to the North Atlantic Oscillation and Climate Variability of Northern Europe, J. Climate, 10, 1635-1647, 1997.

Kalnay, E., Kanamitsu, M., Kistler, R., Collins, W., Deaven, D., Gandin, L., Iredell, M., Saha, S., White, G., Woollen, J., Zhu, Y., Chelliah, M., Ebisuzaki, W., Higgins, W., Janowiak, J., Mo, K. C., Ropelewski, C., Wang, J., Leetmaa, A., Reynolds, R., Jenne, R., and Joseph, D.: The NCEP/NCAR reanalysis project, Bull. Am. Meteorol. Soc., 77, 437-471, 1996.

Kushnir, Y., Cardone, V. J., Greenwood, J. G., and Cane, M. A.: The recent increase in the North Atlantic wave height, J. Climate, 10, 2107-2113, 1997.

Lamb, H. H.: Climatic variations and changes in the wind and ocean circulation: the Little Ice Age in the Northeast Atlantic, Quat. Res., 11, 1-20, 1979.

Lavrenov, I.: Numerical modeling of wind waves in spatially heterogeneous ocean, Gidrometeoizdat, St. Petersburg, 449 pp., 1998 (in Russian).

Lionello, P., Bhend, J., Buzzi, A., Della-Marta, P. M., Krichak, S., Jansà, A., Maheras, P., Sanna, A., Trigo, I. F., and Trigo, R.: Cyclones in the Mediterranean region: climatology and effects on the environment, edited by: Lionello, P., Malanotte-Rizzoli, P. and Boscolo, R., in: Developments in Earth and Environmental Sciences, Elsevier, 4, 325-372, 2006.

Lozano, I., Devoy, R. J. N., May, W., and Andersen, U.: Storminess and vulnerability along the Atlantic coastlines of Europe: analysis of storm records and of a greenhouse gases induced climate scenario, Mar. Geol., 210, 205-225, 2004.

Marshall, J., Kushnir, Y., Battisti, D., Chang, P., Czaja, A., Dickson, R., Hurrell, J., McCartney, M., Saravanan, R., and Visbeck, M.: North Atlantic climate variability: phenomena, impacts and mechanisms, Int. J. of Climatology, 21, 1863-1898, 2011.

Matulla, C., Schöner, W., Alexandersson, H., von Storch, H., and Wang, X. L.: European storminess: late nineteenth century to present, Clim. Dynam., 31, 125-130, 2008.

Mishev, K., Popov, V., Dimitrov, V., Valkanov, A., and Rozhdestvenski, A.: Physical and geographical features, in: Black Sea - collection. Publ. House "G.Bakalov", Varna, edited by: Valkanov, A., Marinov, H., Danov, H, and Vladev, P., 35-86, 1978 (in Bulgarian).

National Statistical Institute (NSI): 2011 Population Census in the Republic of Bulgaria (final data), 51 pp., www.nsi.bg/ census2011/PDOCS2/Census2011final_en.pdf, 2011.

Nicholls, R. J., Wong, P. P., Burkett, V. R., Codignotto, J. O., Hay, J. E., McLean, R. F., Ragoonaden, S., and Woodroffe, C. D.: Coastal systems and low-lying areas. Climate Change 2007: Impacts, Adaptation and Vulnerability, in: Contribution of Working Group II to the Fourth Assessment Report of the Intergovernmental Panel on Climate Change, edited by: Parry, M. L., Canziani, O. F., Palutikof, J. P., van der Linden P. J., and Hanson, C. E., Cambridge University Press, Cambridge, UK, 315-356, 2007.

Özhan, E., Abdalla, S., and Yılmaz, N.: Wind and wave climate of the Black Sea, Proc. of 2nd Int. Conf. Oceanography of the Eastern Mediterranean and the Black Sea, Ankara, Turkey, 189195, 2003.

Özhan, E. and Abdalla, S.: Wind-wave climate of the Black Sea and the Turkish coast (NATO TU-WAVES project), Proc. 5th Int. Workshop on Wave Hindcasting and Forecasting, Melbourne, Florida, USA, 71-82, 1998.

Polonsky, A. B., Basharin, D. V., Voskresenskaya, E. N. and Worley, S.: North Atlantic Oscillation: Description, Mechanisms, and Influence on the Eurasian Climate Physical Oceanography, 14, 96-113, doi:10.1023/B:POCE.0000037873.85289.6e, 2004.

Polonsky, A. B., Bardin, M. Yu., and Voskresenskaya, E. N.: Statistical characteristics of cyclones and anticyclones over the Black Sea in the second half of the 20th century, Phys. Oceanogr., 17, 348-359, 2007.

Polonsky, A. B.: Global warming, large-scale processes in the ocean-atmosphere system, thermohaline catastrophe and their impact on climate of the North Atlantic region, in: Use of satellite and in-situ data to improve sustainability, edited by: Kogan, F., Powell, A., and Fedorov, O., NATO Science for Peace and Security Series, C: Environmental Security, Springer Science \& Business Media B. V., 125-143, doi:10.1007/978-90-481-9618$0,2011$.

Polonsky, A. B., Shokurova, I. G., and Belokopytov, V. N.: Decadal variability of the Black Sea temperature and salinity fields, submitted, Oceanology, 2012 (in Russian).

Regnauld, H., Binois, S., Fouqué, Ch. and Lemasson, L.: Micro to mesoscale evolution of beaches in response to climatic shift: observation and conceptual modelling (Brittany France), Geologie Mijnbouw, 77, 323- 332, 1999.

Rusu, E., Rusu, L., and Soares, C. G.: Assessing of extreme wave conditions in the Black Sea with numerical models, paper presented at the 9th International Workshop on Wave Hindcasting and Forecasting, Victoria, Canada, 2006.

Rusu, E.: Wave energy assessments in the Black Sea, J. Mar. Sci. Technol., Springer, 14, 3, 359-372, 2009.

Rzheplinkskij, G.: Wind and Wave Atlas of the Black Sea. Gidrometeoizdat, Leningrad, 111 pp., 1969 (in Russian).

Sánchez-Arcilla, A., Hoekstra, P., Jiménez, J. E., Kaas, E., and Maldonado, A.: Climate implications for coastal processes, in: Sea Level Change and Coastal Processes: Implications for Europe, edited by: Smith, D. E., Raper, S. B., Zerbini, S., and Sánchez-Arcilla, A., European Commission, Brussels, 173-213, 2000.

Simonov, A. I. and Altman, E. N.: Hydrometeorology and Hydrochemistry of the USSR Seas, Vol. 4 - "The Black Sea", No.1 "Hydro-meteorological Conditions". Gidrometeoizdat, St. Petersburg, 429 pp., 1991 (in Russian).

Schmith, T.: Development of occurrence and strength of severe winds over the Northeast Atlantic during the past 100 years, Proc. of the 6th International Meeting on Statistical Climatology, Galway, Ireland, 83-86, 1995.

Sorkina, A. I.: Climatic Handbook of the Black Sea, Gidrometeoizdat, Moscow, 406 pp., 1974 (in Russian).

Stakev, M.: About the break-down state of some coastal structures after the storm in February 1979, Shipbuilding and Navigation, 10, 26-30, 1980 (in Bulgarian).

Sterl, A. and Caires S.: Climatology, variability and extrema of ocean waves - The web-based KNMI/ERA-40 wave atlas, Int. 
J. Climatol., 963-977, doi:10.1002/joc.1175, 2005.

Sterl, A., Komen, G. J., and Cotton, P. D.: Fifteen years of global wave hindcasts using winds from the European Centre for Medium-range Weather Forecasts reanalysis: validating the reanalysed winds and assessing the wave climate, J. Geophys. Res., 103, 5477-5492, 1998.

Steward, J. S., Virnstein, R. W., Lasi, M. A., Morris, L. J., Miller, J. D., Hall, L. M., and Tweedale, W. A.: The Impacts of the 2004 Hurricanes on Hydrology, Water Quality, and Seagrass in the Central Indian River Lagoon, Florida, Estuar. Coast., 29, 954965, 2006.

The SWAN Team: SWAN User Manual, Delft University of Technology, 2006.

Tishkov, H.: The winters in Bulgaria and their changing nature in the 20th century, Problems of Geography. 3, 24-38, 1991 (in Bulgarian).

Trifonov, V. and Trifonova, L.: Typification of synoptic situations initiating high waves along Black Sea coast, Problems of Geography, 2, 42-47, 1988 (in Bulgarian).

Trifonova, E., Valchev, N., Andreeva, N., and Eftimova, P.: Critical storm thresholds for morphological changes in the western Black Sea coastal zone, Geomorphology, 143-144, 81-94, doi:10.1016/j.geomorph.2011.07.036, 2012.

Uppala, S. M., Kallberg, P. W., Simmons, A. J., Andrae, U., Bechtold, V. D., Fiorino, M., Gibson, J. K., Haseler, J., Hernandez, A., Kelly, G. A., Li, X., Onogi, K., Saarinen, S., Sokka, N., Allan, R. P., Andersson, E., Arpe, K., Balmaseda, M. A., Beljaars, A. C. M., Van De Berg, L., Bidlot, J., Bormann, N., Caires, S., Chevallier, F., Dethof, A., Dragosavac, M., Fisher, M., Fuentes, M., Hagemann, S., Holm, E., Hoskins, B. J., Isaksen, L., Janssen, P. A. E. M., Jenne, R., McNally, A. P., Mahfouf, J. F., Morcrette, J. J., Rayner, N. A., Saunders, R. W., Simon, P., Sterl, A., Trenberth, K. E., Untch, A., Vasiljevic, D., Viterbo, P., and Woollen, J.: The ERA-40 Re-analysis, Q. J. Roy. Met. Soc., 131, 29613012, 2005.
Valchev, N., Pilar, P., Cherneva, Z., and Soares, C.G.: Set-up and validation of a third-generation model for the Black Sea, Proc. 7th Int. Conf. on Marine Sciences and Technologies "BLACK SEA'2004", 273-279, 2004.

Valchev, N., Davidan, I., Belberov, Z., and Palazov, A.: Practicability of wind waves simulations based on the global reanalysis wind fields in the Black Sea deep and shallow waters, 4th Int. Conf. "Port Development and Coastal Environment - 2007", Varna, Bulgaria, 185-191, 2007.

Valchev, N., Davidan, I., Belberov, Z., Palazov, A., and Valcheva, N.: Estimation of wind wave climate of the Western Black Sea during the last 50 years, Proc. of 9th Int. Conf. on Marine Sciences and Technologies "BLACK SEA'2008”, 231-239, 2008.

Valchev, N. and Trifonova, E.: Wave climate clustering to define threshold values with respect to the expected morphological response, J. Coastal Res., SI 56 (Proceedings of the 10th International Coastal Symposium), Lisbon, Portugal, 1666-1670, 2009.

Vassilev, T.: On the peculiarities of the heavy storms along the Bulgarian Black Sea coast during years 1976-1979, Hydrology and Meteorology, Sofia, 1, 53-56, 1980 (in Bulgarian).

Voskresenskaya, E. N. and Maslova, V. N.: Winter-spring cyclonic variability in the Mediterranean - Black Sea region associated with global processes in the ocean-atmosphere system, Adv. Sci. Res., 6, 237-243, doi:10.5194/asr-6-237-2011, 2011.

WASA Group: Changing waves and storms in the northeast Atlantic?, Bull. AMS, 79, 741-760, 1998.

Weisse, R. and Günther, H.: Wave climate and long-term changes for the Southern North Sea obtained from a high-resolution hindcast 1958-2002, Ocean Dynam., 57, 161-172, 2007.

Weisse, R., von Storch, H., and Feser, F.: Northeast Atlantic and North Sea storminess as simulated by a regional climate model 1958-2001 and comparison with observations, J. Climate, 18, 465-479, doi:10.1175/JCLI-3281.1, 2005. 